\title{
Mapping cognitive translation and interpreting studies: A bibliometric approach
}

\author{
Christian Olalla-Soler \\ MC2 Lab, University of Bologna, Italy \\ christian.olalla@unibo.it \\ https://orcid.org/0000-0001-9251-476X \\ Javier Franco Aixelá \\ University of Alicante, Spain \\ javier.franco@gcloud.ua.es \\ https://orcid.org/0000-0001-6846-7182 \\ Sara Rovira-Esteva \\ Autonomous University of Barcelona, Spain \\ sara.rovira@uab.cat \\ https://orcid.org/0000-0001-7647-6417
}

\begin{abstract}
This article identifies the specific characteristics of Cognitive Translation and Interpreting Studies (CTIS) as a branch of Translation and Interpreting Studies (TIS), adopting a bibliometric approach. The main data source for this study was the Bibliography of Interpreting and Translation (BITRA), which - as at September 2019 - included more than 77,000 TIS records, covering the diversity of languages and document types used in TIS research. BTRA is the only TIS database to feature citing information. CTIS-related records were analysed, and those published between 1976 and 2015 were compared with the whole corpus of TIS research output for the same period - again, as registered in BITRA. Specifically, we analysed: (a) the general features and evolution of CTIS publications over time (by thematic co-occurrence, by title content words, by format and by language); (b) authorship, focusing on co-authorship and on the most productive authors; (c) the citation patterns of CTIS documents, including a brief analysis of its most cited authors and publications; and (d) CTIS accessibility through a study of the ratio of documents published in open access. These aspects were analysed both synchronically and diachronically so as to describe CTIS as a whole and to identify any changes over time. Our results yield a first overview of CTIS from a bibliometric perspective and provide a methodological point of departure for future bibliometric studies in this area.
\end{abstract}

Keywords: cognitive translation and interpreting studies; bibliometrics; citation patterns; authorship patterns; thematic co-occurrence 
Olalla-Soler, C., Franco Aixelá, J., \& Rovira-Esteva, S. (2020). Mapping cognitive translation and interpreting studies: A bibliometric approach. Linguistica Antverpiensia, New Series: Themes in Translation Studies, 19, 25-52.

\section{Introduction}

Cognitive Translation and Interpreting Studies (CTIS) has been designated in various ways. The main approaches are translation process research, cognitive translatology and cognitive translation studies. Whereas these designations are used as synonyms in many cases, Jääskeläinen and Lacruz (2018) identify several differences in the definitions given to each of them. For the purposes of this article, we employ the designation "cognitive translation and interpreting studies", defined as "cognitive and psycholinguistic approaches to translation and interpreting" (Muñoz Martín, 2016b, p. 9). This definition also encompasses cognitive translatology ("a concrete theoretical framework within Cognitive Translation Studies"; Muñoz Martín, 2016b, p. 9) and translation process research ("a special descriptive, empirical, experimental approach to translation studies based on close, technology-supported observation of translational (micro)behavior"; Jakobsen, 2014, p. 65).

In line with the general evolution of Translation and interpreting Studies (TIS), the number of publications devoted to CTIS has grown rapidly in recent years, whereas CTIS records of documents published from 2006 to 2015 represent 3.3\% of all TIS records of documents published in the same period, CTIS documents published from 2016 to 2019 represent 5.6\% of TIS documents (see Section 3). With less than a score of studies detected before 1971 and approximately 2,000 by 2019 , more than half of all CTIS research output has been published in the past ten years. CTIS could possibly be regarded as a relatively autonomous subdiscipline (see, e.g., Gambier \& van Doorslaer, 2016), and in any case as a consolidated subfield within TIS, given the expansion of research topics in CTIS, the increasing number of scholars conducting CTIS and the boom in themed volumes (e.g., Alves, 2003; Göpferich et al., 2009; Muñoz Martín, 2014b, 2016a; Schwieter \& Ferreira, 2017). To these we must add the conferences devoted exclusively to CTIS, such as the two editions of the biennial International Conference on Translation, Interpreting and Cognition (2017, 2019), the six editions of the yearly International Conference on Cognitive Research on Translation and Interpreting (2014-2019) and the six editions of the biennial Translation Process Research Workshop (2009-2019).

Despite the growth of CTIS in recent years, though, there is a dearth of research oriented towards identifying and describing the characteristics of CTIS as a branch or sub-discipline that may feature a profile of its own within TIS. To our knowledge, the sole exception is Muñoz Martín's (2014a) overview of the advances in CTIS from 2006 to 2013 as measured by themed publications and specific research topics. Muñoz Martín identified 11 books and more than 100 book chapters devoted to translation process research (TPR) published mainly by John Benjamins and Samfundslitteratur. In the list of translation and interpreting journals indexed in the SClmago Journal Rank at that time, Muñoz Martín identified 200 articles devoted to TPR, finding in addition that there had been a sharp increase in the number of articles published in 2011, 2012 and 2013 compared to the previous years. ${ }^{1}$ Regarding the most productive research topics, Muñoz Martín identified the following: competence and expertise, writing, mental load, linguistic complexity, advances in research methods, revision, and metacognition. He also identified new foci of interest, namely, the study of emotions, intuitions, behavioural styles and uncertainty management, among others. 
Olalla-Soler, C., Franco Aixelá, J., \& Rovira-Esteva, S. (2020). Mapping cognitive translation and interpreting studies: A bibliometric approach. Linguistica Antverpiensia, New Series: Themes in Translation Studies, 19, 25-52.

Bibliometrics - broadly defined as "the statistical study of (the flux of) information" (RoviraEsteva \& Franco Aixelá, 2018, p. 117) - has many applications. An essential one is describing a discipline, both synchronically and diachronically, by identifying patterns and regularities in the flux of its published information. While bibliometrics is a relatively new research approach in TIS, a growing body of (meta-)studies aim at describing our discipline, with more than 100 TS-oriented bibliographic and bibliometric studies detected in the 21st century. ${ }^{2}$

The main objective of this article is twofold. First, we want to describe and explain the evolution of CTIS since its inception, applying a bibliometric approach. Second, we aim to identify the specific characteristics of CTIS as a branch of TIS by comparing the results of our study with the general characteristics of TIS. In line with these goals and using the Bibliography of Interpreting and Translation (BITRA) as our main data source, we aim to provide data and insights about the following research issues:

1. The global evolution of research

2. Research topics

3. Publication languages

4. Publication formats

5. Authorship patterns

6. Citation behaviour and productivity

7. Open versus toll access.

This article is structured as follows. Section 2 describes the data sources and the methods employed for this study. Section 3 presents the results, organized into four sections: (3.1) the evolution and characteristics of CTIS publications; (3.2) authorship in CTIS; (3.3) citation patterns in CTIS, and (3.4) accessibility of CTIS documents. Finally, we present our conclusions and discuss the research perspectives and the limitations of our study.

\section{Data sources and methods}

The data employed to provide answers to the research questions posed in Section 1 were mainly retrieved from BITRA, an open-access (OA), holistic bibliographic TIS database (Franco Aixelá, 2001-2020) with more than 77,000 items as at September 2019. BITRA attempts to cover a wide variety of document formats (journal articles, book chapters, books, PhD theses, journal special issues and journals) and languages - records refer to documents in more than 50 languages, of which $99.8 \%$ are in English, Spanish, French, German, Portuguese, Italian, Chinese and Catalan. BITRA also includes citation data from more than $10 \%$ of its entries, with more than 100,000 citations already assigned to the cited documents. In its citation-mining process, BITRA attempts to cover all kinds of format and a wide range of geographical and language origins, although the mined publications feature a larger presence of more recent publications, Western languages and shorter formats for operational reasons. ${ }^{3}$

In September 2019, BITRA listed 77,660 entries, 2,008 of which (2.6\%) were labelled as belonging to CTIS. This figure includes both empirical studies and theoretical investigations related to CTIS. Assigning thematic categories to scientific publications is not an easy or a straightforward task. Whereas in some cases the topic of a publication falls clearly into a 
Olalla-Soler, C., Franco Aixelá, J., \& Rovira-Esteva, S. (2020). Mapping cognitive translation and interpreting studies: A bibliometric approach. Linguistica Antverpiensia, New Series: Themes in Translation Studies, 19, 25-52.

specific thematic category, often a single document may cover several topics or deal with them from different perspectives. To ensure that the publications originally catalogued in BITRA as belonging to CTIS were in fact devoted to CTIS, each publication was independently screened by the three authors in order to identify - based on the title and the abstract (and sometimes even the article itself) - which publications should be excluded from the corpus of CTIS publications. The main criterion we applied was that CTIS documents should be devoted to any of the most frequent research topics in the field (see Muñoz Martín 2014a for a list of both frequently investigated and emerging topics) or that they should be closely related to any of them. Collective books that were not exclusively devoted to CTIS were excluded, but not the chapters in those books that were devoted to CTIS. Discrepancies in the authors' independent screening results were settled through a close examination of the document followed by a joint decision.

To assess the representativeness of the corpus of publications devoted to CTIS, we contrasted it with the Translation Studies Bibliography database (TSB, Gambier \& van Doorslaer, 2020). In this process we identified the following:

- 84 records associated with CTIS that had not been indexed in BITRA, 54 (2.7\% of the initial sample) of which were considered suitable for our corpus.

- $1,137(56,6 \%)$ records indexed as CTIS in BITRA were not found in TSB.

In all, from the initial corpus of 2,008 records identified in BITRA,

- 18 were discarded because they were not considered to deal with CTIS,

- 84 records indexed as non-CTIS in BITRA were relabelled as CTIS, and

- 54 TSB registers not indexed in BITRA were added.

The final corpus comprised 2,128 records devoted to CTIS and 77,714 devoted to TIS. The original BITRA corpus of 2,008 CTIS records corresponded to $94.3 \%$ of the final corpus of 2,128 CTIS publications.

An ad-hoc database was created by exporting and converting to a spreadsheet file the following data fields in BITRA: the documents' author(s), publication year, title, publisher, publication format, language of publication, thematic labels, accessibility (open access vs toll access) and citation data (author and citation year).

We present and analyse the whole CTIS corpus throughout this article. In order to compare the features of CTIS with those of TIS, we had to decide on a comparable period. After analysing the distribution of publications in CTIS (see Section 3.1.1), we selected 1976 as the starting point of analysis, since the number of records of published documents devoted to CTIS before that year is rather anecdotal (only 37 records before 1976). When comparing CTIS with TIS, all records of documents published in CTIS and TIS in and before 1975 were discarded. As an upper limit, we discarded all records of documents published after 2015, given that in databases covering living disciplines the ratio of more recent documents is not as high as in previous years - a regular coverage of a given year takes about three years to achieve. Furthermore, a recommended citation window for TIS is approximately six years (Rovira-Esteva et al., 2019). Accordingly, our period of analysis for comparing CTIS to TIS is 
Olalla-Soler, C., Franco Aixelá, J., \& Rovira-Esteva, S. (2020). Mapping cognitive translation and interpreting studies: A bibliometric approach. Linguistica Antverpiensia, New Series: Themes in Translation Studies, 19, 25-52.

from 1976 to 2015. When looking at the evolution of CTIS, we also established four decades for which to obtain a more detailed picture: 1976-1985, 1986-1995, 1996-2005 and 20062015.

To analyse the thematic occurrence of CTIS records and compare it with that of TIS records, we used BITRA's thematic labels. In BITRA, most thematic labels are part of a controlledlanguage list, whereas others, such as the names of analysed authors and works, are open and assigned according to the characteristics of each publication. For this analysis, we selected only the controlled thematic labels in order to facilitate the comparison between CTIS and TIS records. We selected all the thematic labels that occurred with a minimum frequency of two per cent. This threshold was established after observing the thematic distribution of both CTIS and TIS. We detected that the number of thematic labels obtained with that minimum percentage stayed at a manageable level for a subsequent analysis without losing relevant labels.

To refine these results - and taking advantage of the fact that BITRA provides an English translation of the titles for all non-English records - we extracted the content words from the titles of all CTIS records between 1976-2015. To do so, all stop words (such as the, $a$, an, in or and) were deleted and each content word was manually identified and assigned to a category, depending on the kind of information it conveyed:

- a reference to a conceptual framework for a study;

- the languages employed;

- the methods;

- the participants;

- the professional fields; and

- the topic under investigation.

The resulting list of content words underwent two cleaning phases to identify similar content words that could be unified into a single one (e.g., simultaneous interpreting + simultaneous interpretation or survey + survey-based study + survey-based research, etc.). The results section provides the content words by category with a frequency of occurrence in at least five records, except for the content-word category related to research topics. We identified more than 2,000 different topics and the list would have been too long for the purposes of this article; accordingly, in this case, we offer the ten most frequent research topics in CTIS.

We created co-authorship networks in CTIS using VOSviewer version 1.6 .15 (van Eck \& Waltman, 2010). All the authors in CTIS documents published from 1976 to 2015 were extracted from the records and checked for coherence in their spelling. Then we plotted a network graph containing all the CTIS authors of the publications in the chosen period. Given that the whole period of analysis was used, we needed to normalize our data so that all the documents had the same weight independently of the number of years their authors have been actively publishing documents. For this reason, we employed fractional counting (Perianes-Rodriguez et al., 2016) when constructing the network. 
Olalla-Soler, C., Franco Aixelá, J., \& Rovira-Esteva, S. (2020). Mapping cognitive translation and interpreting studies: A bibliometric approach. Linguistica Antverpiensia, New Series: Themes in Translation Studies, 19, 25-52.

When investigating citation patterns in CTIS and TIS, we observed that periods of analysis and publication types present different densities of publication, that is, the distribution of the frequency of each possible publication type in the dataset. This could affect the quality of the analysis since, for example, we would be giving the same weight to a document published 30 years ago and cited only once and to a document published two years ago with also only a single citation. Moreover, Rovira-Esteva et al. (2019) determined that some publication formats in TIS tend to accrue more citations than others. For this reason, we normalized our citation data, that is, we applied a corrective factor to adjust for differences in the density of publications (De Bellis, 2009), in terms of both time and document type. To perform this normalization, we calculated the mean number of citations accrued by all the documents published in a specific year and in a specific publication format (expected citations) and we divided the observed citations of a publication with the same format and publication year by the expected citations. This procedure was performed for every document type (journal article, book chapter, book, journal special issue and $\mathrm{PhD}$ thesis) and for every year included in the comparative analysis (1976-2015).

When investigating citation patterns in terms of citation latency (i.e., the time between publication and first citation) for a document and its cited half-life ("the time during which half the total use of a given literature has been made"; De Bellis, 2009, p. 114), we normalized the citation latency, in years, for each publication type by applying Moed, Van Leeuwen and Reedijk's correction (1999). We created life tables and plotted the cumulative distribution of the survival function for each of the two factors investigated (citation latency to receive the first citation and cited half-life). In this article, only the plots are presented for reasons of space. The cumulative distribution of the survival function provides the likelihood of a document being cited beyond any given specified time. For this calculation, records for which no citation was detected during the whole period of analysis were used as censored cases, that is, cases in which the condition of being cited has not been accomplished within the specified time period.

By the time this study was conducted, BITRA had extracted citation data from 10 per cent of its records, with more than 100,000 citations assigned to the cited documents. Consequently, the results in the citation pattern and latency analyses should be interpreted with caution. Despite this limitation, we chose BITRA as a source of citation data because:

(1) BITRA excludes self-citations, a phenomenon that has been extensively researched in bibliometrics and has been found to distort results (Cooke \& Donaldson, 2014).

(2) BITRA is a TIS-specific database and therefore does not index or extract citations from or to documents outside this field. This is essential to carrying out citation and latency analyses, as field-normalized data are required to avoid distortions in the results (De Bellis, 2009).

(3) Except for PhD theses, BITRA does not index "grey" literature (Schöpfel \& Farace, 2010) such as Master's theses or conference presentations, to name but two.

Consequently, the assigning of citations is carried out with documents that have been subject to academic filters (mostly peer or publisher review) before being published. Other sources of citation data, such as Scopus and Web of Science, do not meet (some of) these criteria and their use for citation and latency analysis purposes in TIS would greatly distort the results. 
Olalla-Soler, C., Franco Aixelá, J., \& Rovira-Esteva, S. (2020). Mapping cognitive translation and interpreting studies: A bibliometric approach. Linguistica Antverpiensia, New Series: Themes in Translation Studies, 19, 25-52.

Google Scholar features the largest citation coverage but lacks appropriate labels for an automated simultaneous treatment of the data. For this reason, using it would have involved months of work in data-cleansing and citation-extraction, not to mention that when the citation count for the last publication was found and recorded, the first mined publications would already have changed their figures.

Regarding statistical analysis, distributions based on bibliometric data are "markedly skewed, conforming to a hyperbolic pattern" (De Bellis, 2009, pp. 77, 84-88, 209). Even when large amounts of data are employed, these are not normally distributed, making it difficult to justify the use of parametric tests that require normally distributed data. Hence, we use nonparametric tests - especially, the Mann-Whitney $U$ test - to compare CTIS and TIS trends. For all the tests we report on the effect sizes $(r)$. In order to include only reliable results, we consider that $r$ values below 0.3 (Ellis, 2010) are not relevant to our study, even when the result of the test is statistically significant. When comparing categorical data, we employ the chi-squared test (and Cramér's $V$ as an effect-size measure) and Fisher's exact test to compare binomial data.

\section{Results and discussion}

\subsection{Evolution and characteristics of CTIS publications}

\subsubsection{A diachronic review of CTIS publications}

Figure 1 below shows the number of records dealing with CTIS. They have been grouped in complete decades for the 1956-2015 period (1956-1965, 1966-1975, 1976-1985, 19861995, 1996-2005 and 2006-2015), whereas the very few records of documents published until 1955 have been grouped together separately. The records of documents published until 1975 were scarce (37), amounting to just over a half the number of those published in the 1976-1985 decade (71). After 1986, CTIS gains momentum, especially in the 1996-2005 decade. Based on these descriptive results, we distinguish three development phases in CTIS:

(a) a seminal phase (until 1975), which is partially aligned with the development of modern TIS (Snell-Hornby, 2006);

(b) an initial phase from 1976-1995, in which there is a consistent growth of interest for CTIS within TIS, and during this period many of the most-cited CTIS documents are published (see Section 3.3.1);

(c) a rooting phase (starting 1996), in which the number of CTIS publications grows at a very rapid pace and the area opens up to many new sub-topics, greatly broadening its research scope. 
Olalla-Soler, C., Franco Aixelá, J., \& Rovira-Esteva, S. (2020). Mapping cognitive translation and interpreting studies: A bibliometric approach. Linguistica Antverpiensia, New Series: Themes in Translation Studies, 19, 25-52.

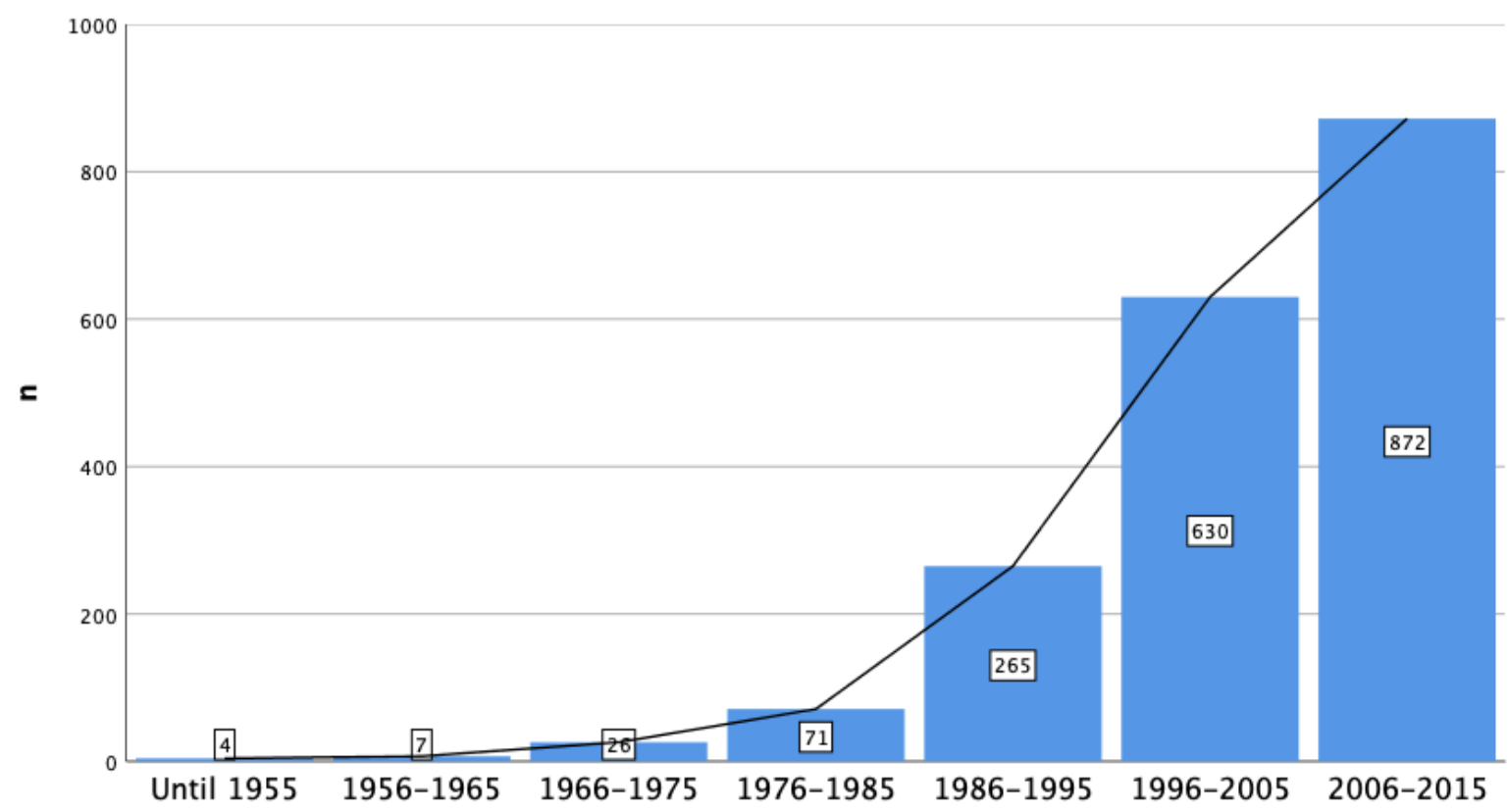

Figure 1. Number of CTIS publications over time

The records included in the seminal phase (until 1975) were mainly single-authored journal articles (62.2\%), and written mainly in English (54.1\%), with a notable presence of German (29.7\%). The first detected document devoted to CTIS was published in 1910: an article authored by Gabriele von Wartensleben titled Beiträge zur Psychologie des Übersetzens (Contributions to the psychology of translation). We found 32 authors during this phase, and Kade was the most productive of them, with three contributions to CTIS. These documents were published mainly in psychology journals (such as Perception \& Psychophysics, the British Journal of Psychology and the Journal of Experimental Psychology) and they were generally devoted to interpreting (34\%), specifically to simultaneous interpreting and how the brain works in order to be able to use two languages simultaneously.

The data suggest that the inception of CTIS occurs at the end of the 1970s and in the 1980s (the initial phase). During these years, many seminal works were written (see Section 3.3.1).

During the rooting phase (starting in 1996), the number of books, book chapters and articles increases sharply. This increase is also aligned with the many academic CTIS-related events during this phase: specific panels devoted to CTIS at international conferences such as the EST, ABRAPT, IATIS and AIETI conference series, specific conferences on CTIS such as the TPR workshops (starting in 2009), the two editions of the International Congress on Translation, Interpreting and Cognition (starting in 2017), and the six editions of the International Conference on Cognitive Research on Translation and Interpreting (starting in 2014). Such events were frequently accompanied by the publication of conference proceedings, which would explain part of the increase in publications during this phase. The creation of the network Translation, Research, Empiricism and Cognition (TREC) in 2011 probably had an influence on the increase in co-edited and co-authored documents, such as the special issue on translation process research published in Translation \& Interpreting (2015) and co-edited 
Olalla-Soler, C., Franco Aixelá, J., \& Rovira-Esteva, S. (2020). Mapping cognitive translation and interpreting studies: A bibliometric approach. Linguistica Antverpiensia, New Series: Themes in Translation Studies, 19, 25-52.

by Giozza (Argentina), Jääskeläinen (Finland), Mellinger (United States) and Rodríguez-Inés (Spain). Finally, in 2018, the first journal devoted to CTIS was launched: Translation, Cognition \& Behavior (John Benjamins), edited by Muñoz Martín.

Out of a total of 77,714 TIS publications indexed in BITRA, $2.7 \%(2,128)$ records deal with CTIS. Table 1 below presents (a) the percentage of CTIS records published in the periods shown in Figure 1; (b) the percentage of TIS records published in the same periods; (c) the percentage of CTIS records published within TIS in each period. In all, $52.8 \%$ of the CTIS contributions have been published since 2006 , whereas $40 \%$ of the TIS contributions have been published since that same year. In 2006-2015, the CTIS publications represent 3.3\% of all TIS publications. As mentioned, this ratio has continued to grow and has reached $5.6 \%$ of all TIS publications for the 2016-2019 period.

Table 1. A comparative distribution of CTIS and TIS publications

\begin{tabular}{|c|c|c|c|c|}
\hline & \multicolumn{4}{|c|}{ Percentage of records } \\
\hline & CTIS $(n=2,128)$ & TIS & $(n=77,714)$ & CTIS within TIS \\
\hline Until 1955 & 0.2 & 2.0 & $(n=1,555)$ & 0.3 \\
\hline $1956-1965$ & 0.3 & 1.5 & $(n=1,172)$ & 0.6 \\
\hline $1966-1975$ & 1.2 & 2.7 & $(n=2,116)$ & 1.2 \\
\hline $1976-1985$ & 3.3 & 5.7 & $(n=4,467)$ & 1.6 \\
\hline $1986-1995$ & 12.5 & 15.3 & $(n=11,863)$ & 2.2 \\
\hline $1996-2005$ & 29.6 & 32.8 & $(n=25,463)$ & 2.5 \\
\hline $2006-2015$ & 41.0 & 34.2 & $(n=26,572)$ & 3.3 \\
\hline $2016-2019$ & 11.8 & 5.8 & $(n=4,506)$ & 5.6 \\
\hline
\end{tabular}

\subsubsection{Thematic occurrence}

Table 2 shows BITRA's thematic labels assigned to at least $2 \%$ of CTIS and TIS records. In CTIS, thematic distribution tends to be more compact than in TIS. Labels related to humanistic research topics such as translation history, poetry or religion do not draw as much interest in CTIS as in TIS. However, training seems to be one of the main foci of both CTIS and TIS, possibly due to the interest in applying research results to the teaching of translation and interpreting. 
Olalla-Soler, C., Franco Aixelá, J., \& Rovira-Esteva, S. (2020). Mapping cognitive translation and interpreting studies: A bibliometric approach. Linguistica Antverpiensia, New Series: Themes in Translation Studies, 19, 25-52.

Table 2. BITRA's thematic labels for CTIS and TIS records with a frequency of $>\mathbf{2} \%(\mathbf{1 9 7 6 - 2 0 1 5})^{4}$

\begin{tabular}{|c|c|c|c|c|c|c|c|}
\hline & \multicolumn{3}{|l|}{ CTIS } & & \multicolumn{3}{|l|}{ TIS } \\
\hline & Topic & $\mathrm{n}$ & $\%$ & & Topic & $\mathrm{n}$ & $\%$ \\
\hline 1 & Training & 363 & 19.7 & 1 & Literature & 19,782 & 28.9 \\
\hline 2 & Interpreting & 363 & 19.7 & 2 & History & 10,719 & 15.7 \\
\hline 3 & $\begin{array}{l}\text { Problem (specific translation } \\
\text { problems) }\end{array}$ & 233 & 12.7 & 3 & Didactics & 9,862 & 14.4 \\
\hline 4 & Text genre (translation modes) & 166 & 9.0 & 4 & Technical translation & 9,118 & 13.3 \\
\hline 5 & Research (methodology) & 151 & 8.2 & 5 & Interpreting & 7,895 & 11.5 \\
\hline 6 & Simultaneous interpreting & 148 & 8.0 & 6 & Spain & 7,428 & 10.9 \\
\hline 7 & Quality & 137 & 7.4 & 7 & Professional aspects & 6,537 & 9.6 \\
\hline 8 & Linguistics & 98 & 5.3 & 8 & History before 20th century & 5,976 & 8.7 \\
\hline 9 & Professional issues & 64 & 3.5 & 9 & Audiovisual translation & 5,302 & 7.8 \\
\hline 10 & Scientific \& technical translation & 64 & 3.5 & 10 & United Kingdom & 4,819 & 7.0 \\
\hline 11 & Machine translation & 63 & 3.4 & 11 & Machine translation & 4,751 & 6.9 \\
\hline 12 & Audiovisual translation & 50 & 2.7 & 12 & English & 4,593 & 6.7 \\
\hline 13 & Meaning & 48 & 2.6 & 13 & Poetry & 4,364 & 6.4 \\
\hline 14 & English & 46 & 2.5 & 14 & Religion & 4,342 & 6.4 \\
\hline 15 & Metaphor & 46 & 2.5 & 15 & France & 4,299 & 6.3 \\
\hline 16 & Literature & 39 & 2.1 & 16 & Linguistics & 4,098 & 6.0 \\
\hline & & & & 17 & Novel & 3,753 & 5.5 \\
\hline & & & & 18 & History: 20th \& 21st centuries & 3,541 & 5.2 \\
\hline & & & & 19 & Legal translation & 3,450 & 5.0 \\
\hline & & & & 20 & Bible & 3,433 & 5.0 \\
\hline & & & & 21 & United States & 3,375 & 4.9 \\
\hline & & & & 22 & Translation policies & 2,917 & 4.3 \\
\hline & & & & 23 & Quality & 2,888 & 4.2 \\
\hline & & & & 24 & Germany & 2,878 & 4.2 \\
\hline & & & & 25 & Theatre & 2,726 & 4.0 \\
\hline & & & & 26 & Italy & 2362 & 3.5 \\
\hline & & & & 27 & Spanish & 2,313 & 3.4 \\
\hline & & & & 28 & Ideology & 2,191 & 3.2 \\
\hline & & & & 29 & Documentation & 2,052 & 3.0 \\
\hline & & & & 30 & Research & 2,035 & 3.0 \\
\hline & & & & 31 & China & 2,034 & 3.0 \\
\hline & & & & 32 & Grammar & 2,030 & 3.0 \\
\hline & & & & 33 & Culture & 2,026 & 3.0 \\
\hline & & & & 34 & Arabic & 1,904 & 2.8 \\
\hline & & & & 35 & Subtitling & 1,875 & 2.7 \\
\hline & & & & 36 & French & 1,824 & 2.7 \\
\hline & & & & 37 & Medical translation & 1,785 & 2.6 \\
\hline
\end{tabular}

To refine and expand the results of the analysis of the thematic labels in BITRA, we identified content words manually in the titles of CTIS publications (see Table 3). Each content word was tagged according to the information it provided (if any): the conceptual framework employed in the document, the languages as objects of study, the methods employed, the participants in the investigation, the professional fields investigated and the research topics. In all, $74.5 \%$ 
Olalla-Soler, C., Franco Aixelá, J., \& Rovira-Esteva, S. (2020). Mapping cognitive translation and interpreting studies: A bibliometric approach. Linguistica Antverpiensia, New Series: Themes in Translation Studies, 19, 25-52.

of the records were devoted to translation (including localization, subtitling, etc.), $22.1 \%$ to interpreting (including sight translation) and 3.4\% to revision (including post-editing).

Table 3. Most frequent content words in the titles of CTIS publications (1976-2015; 1,758 records)

\begin{tabular}{|c|c|c|c|c|c|}
\hline research topics & $\%$ & conceptual framework & $\%$ & professional fields & $\%$ \\
\hline training & 7.2 & Psycholinguistics & 18.8 & simultaneous interpreting & 40.8 \\
\hline creativity & 4.2 & Psychology & 8.7 & audiovisual translation* & 13.6 \\
\hline translation competence & 3.7 & Cognitive linguistics & 8.2 & post-editing & 11.7 \\
\hline strategy & 2.3 & Neurolinguistics & 4.9 & consecutive interpreting & 6.8 \\
\hline expertise & 1.9 & Relevance theory & 4.6 & conference interpreting & 5.4 \\
\hline comprehension & 1.7 & cognitive translatology & 2.7 & literary translation & 3.8 \\
\hline decision-making & 1.7 & Linguistics & 2.7 & legal translation & 3.0 \\
\hline effort & 1.7 & Cognitive psychology & 2.4 & technical translation & 2.4 \\
\hline metaphor & 1.7 & Ergonomics & 2.2 & scientific translation & 1.9 \\
\hline reading & 1.7 & Semantics & 2.1 & dialogue interpreting & 1.6 \\
\hline working memory & 1.4 & Neurocognition & 1.4 & sign language interpreting & 1.6 \\
\hline culture & 1.3 & Cocial cognition & 1.4 & localization & 1.4 \\
\hline assessment & 1.1 & & & & \\
\hline Languages & $\%$ & Methods & $\%$ & participants & $\%$ \\
\hline English & 22.1 & eye-tracking & 23.7 & professional translators & 26.1 \\
\hline Chinese & 9.2 & think-aloud techniques & 22.7 & translation students & 16.9 \\
\hline Spanish & 7.6 & keylogging & 7.2 & professional interpreters & 11.1 \\
\hline French & 6.8 & retrospection & 5.2 & bilinguals & 4.5 \\
\hline German & 5.6 & corpus-based study & 2.1 & novice translators & 4.1 \\
\hline Japanese & 5.2 & electro-encephalography & 2.1 & interpreting students & 2.9 \\
\hline Portuguese & 3.6 & introspection & 1.7 & non-professional translators & 1.9 \\
\hline Korean & 3.2 & survey & 1.7 & & \\
\hline Arabic & 2.0 & & & & \\
\hline \multicolumn{6}{|c|}{ * Of which, subtitling $71.4 \%$; dubbing $24 \%$ and accessibility $4.6 \%$. } \\
\hline \multicolumn{6}{|c|}{$\begin{array}{l}\text { Note: Each content word has a minimum frequency of five cases, except for those in research topics. There, we identified } \\
\text { more than } 2,000 \text { different topics, so we provide only the ten most frequent topics. The percentages were calculated in } \\
\text { relation to the total number of records that contained a content word of the same category (conceptual framework, } \\
\text { languages, methods, participants or professional fields). The difference between the number of CTIS records analysed here } \\
(1,758) \text { and the total number of CTIS records of documents published from } 1976 \text { to } 2015(1,838) \text { is due to the fact that in } \\
\text { some document titles it was not possible to extract keywords as they were uninformative. }\end{array}$} \\
\hline
\end{tabular}

The analysis of content words indicates that CTIS studies (partially) based on linguistics are very frequent, followed by studies (partially) based on psychology. The conceptual frameworks or "schools" presented in Table 3 account for $63.6 \%$ of the CTIS records indexed in BITRA that refer to any specific framework in the titles. This would seem to indicate that CTIS is highly interdisciplinary.

Eye-tracking and think-aloud studies account for about $50 \%$ of all methodological approaches mentioned in the titles of CTIS publications. However, and as observed in the content word analysis, most CTIS works tend to employ more than a single method to collect data, but in the title of their publications the authors tend not to list all the methods employed. Datacollection methods have consecutively peaked, as TAPs in the 1990s, keylogging in the first decade of the 20th century and eye-tracking in the second decade. Possibly, authors tend to 
Olalla-Soler, C., Franco Aixelá, J., \& Rovira-Esteva, S. (2020). Mapping cognitive translation and interpreting studies: A bibliometric approach. Linguistica Antverpiensia, New Series: Themes in Translation Studies, 19, 25-52.

mention the use of the most-valued method at the time of publishing a document and this is an obstacle to determining the way in which methods have been combined. A closer examination of the abstracts or the methods section of each document would help with resolving this issue.

Concerning the participants, comparing translation professionals $(26.1 \%)$ with translation students $(16.9 \%)$ is one of the most frequent procedures. Including interpreting students $(2.9 \%)$ is not as frequent as having bilinguals $(4.5 \%)$ participate in studies on interpreting. Simultaneous interpreting $(40.8 \%)$ is more frequently investigated than consecutive interpreting (6.8\%) and dialogue interpreting (1.6\%). As discussed, simultaneous interpreting was in fact the main research topic in the seminal phase of CTIS and it has constantly attracted much attention over the years. Audiovisual translation has also attracted much attention in recent years because of the surge in demand of translated audiovisual content (Díaz Cintas \& Massidda, 2019). Post-editing (11.7\%) in CTIS has been a very productive professional field owing to the recent developments in machine translation systems in recent years. Literary translation (3.8\%) is the professional field that has been investigated the most. Concerning research topics, the application of CTIS to training is one of the most frequent objects of study (7.2\%). Possibly the most tangible application of research to the cognitive processes involved in translation or interpretation is identifying ways to improve those processes in future translators and interpreters. Translation competence $(3.7 \%)$, which is partly related to training, is also one of the most investigated topics, preceded by creativity $(4.2 \%)$.

\subsubsection{Publication languages}

Table 4 shows the languages most frequently used in CTIS and in TIS records from 1976 to 2015.

Table 4. Publication languages in CTIS and TIS (1976-2015)

\begin{tabular}{|l|l|r|r|c|}
\hline & & \multicolumn{3}{|c|}{ Use of languages, in percentages } \\
\hline$\#$ & Language & CTIS & TIS & Differential ratios \\
\hline 1 & English & 65.8 & 48.1 & +36.8 \\
\hline 2 & German & 11.5 & 7.7 & +49.4 \\
\hline 3 & Spanish & 8.8 & 19.3 & -54.4 \\
\hline 4 & French & 7.9 & 11.8 & -33.1 \\
\hline 5 & Portuguese & 3.1 & 3.3 & -6.1 \\
\hline 6 & Chinese & 1.3 & 1.6 & -18.8 \\
\hline 7 & Italian & 1.1 & 3.0 & -63.4 \\
\hline 8 & Russian & 0.8 & 0.4 & +100.0 \\
\hline 9 & Polish & 0.5 & 0.5 & 0.0 \\
\hline 10 & Finnish & 0.2 & 0.4 & -50.0 \\
\hline$(1,838$ records in CTIS and 68,364 in TIS $)$ & \\
\hline
\end{tabular}


Olalla-Soler, C., Franco Aixelá, J., \& Rovira-Esteva, S. (2020). Mapping cognitive translation and interpreting studies: A bibliometric approach. Linguistica Antverpiensia, New Series: Themes in Translation Studies, 19, 25-52.

English is more frequent in CTIS records than in TIS records. While this is visible in all periods, the difference is particularly strong in the last period of analysis (2006-2015; see Figure 2), so CTIS seems to tend toward a more widespread use of English as an academic lingua franca than TIS does. German was slightly more frequent in CTIS than in TIS from 1986 to 2015, possibly because many of the most productive authors in CTIS used German in their publications (see Section 3.3.1), but it presents a decreasing trend from the 1986-1995 period onwards.

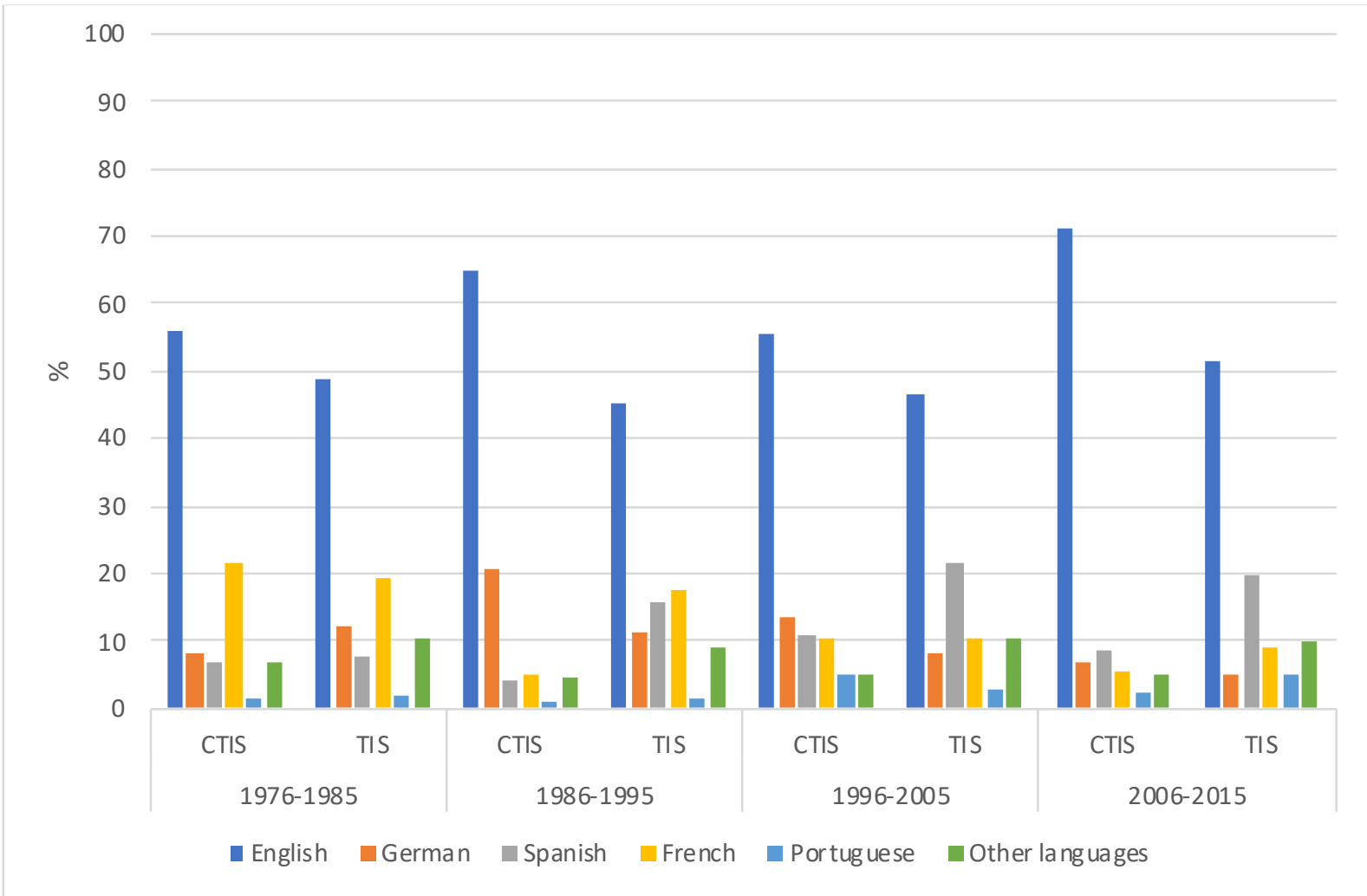

Figure 2. Distribution of the five most-frequent publication languages in CTIS and TIS (1976-2015)

\subsubsection{Publication format}

Table 5 shows the number of records published in each format in CTIS and TIS (1976-2015).

Table 5. Publication formats in CTI and TIS (1976-2015), in percentage

\begin{tabular}{|l|r|c|c|}
\hline & CTIS & TIS & Differential ratios \\
\hline Articles & 42.5 & 43.2 & -1.6 \\
\hline Book chapters & 42.3 & 38.8 & +9.0 \\
\hline Books & 7.7 & 12.3 & -37.4 \\
\hline PhD theses & 6.7 & 4.4 & +52.3 \\
\hline Special issues & 0.8 & 1.0 & -20.0 \\
\hline (1,838 records in CTIS and 68,364 in TIS)
\end{tabular}

Relevant differences between CTIS and TIS were observed only in books and book chapters. ${ }^{5}$ Book chapters are more frequent in CTIS and books are more frequent in TIS. This could be a 
Olalla-Soler, C., Franco Aixelá, J., \& Rovira-Esteva, S. (2020). Mapping cognitive translation and interpreting studies: A bibliometric approach. Linguistica Antverpiensia, New Series: Themes in Translation Studies, 19, 25-52.

result of CTIS research tending to be published in edited book volumes with chapters by different authors, whereas in TIS the proportion of single-authored monographs is higher. The following calculation cannot be considered entirely objective, since not all books are edited volumes containing book chapters; nevertheless, there is a ratio of 5.5 chapters per book in CTIS and 3.2 in TIS (see Table 5). The proportion of PhD theses in CTIS (6.9\%) appears to be slightly higher than in TIS (4.4\%) and diachronically (see Figure 3) PhD theses also more frequent in CTIS than in TIS in all periods.

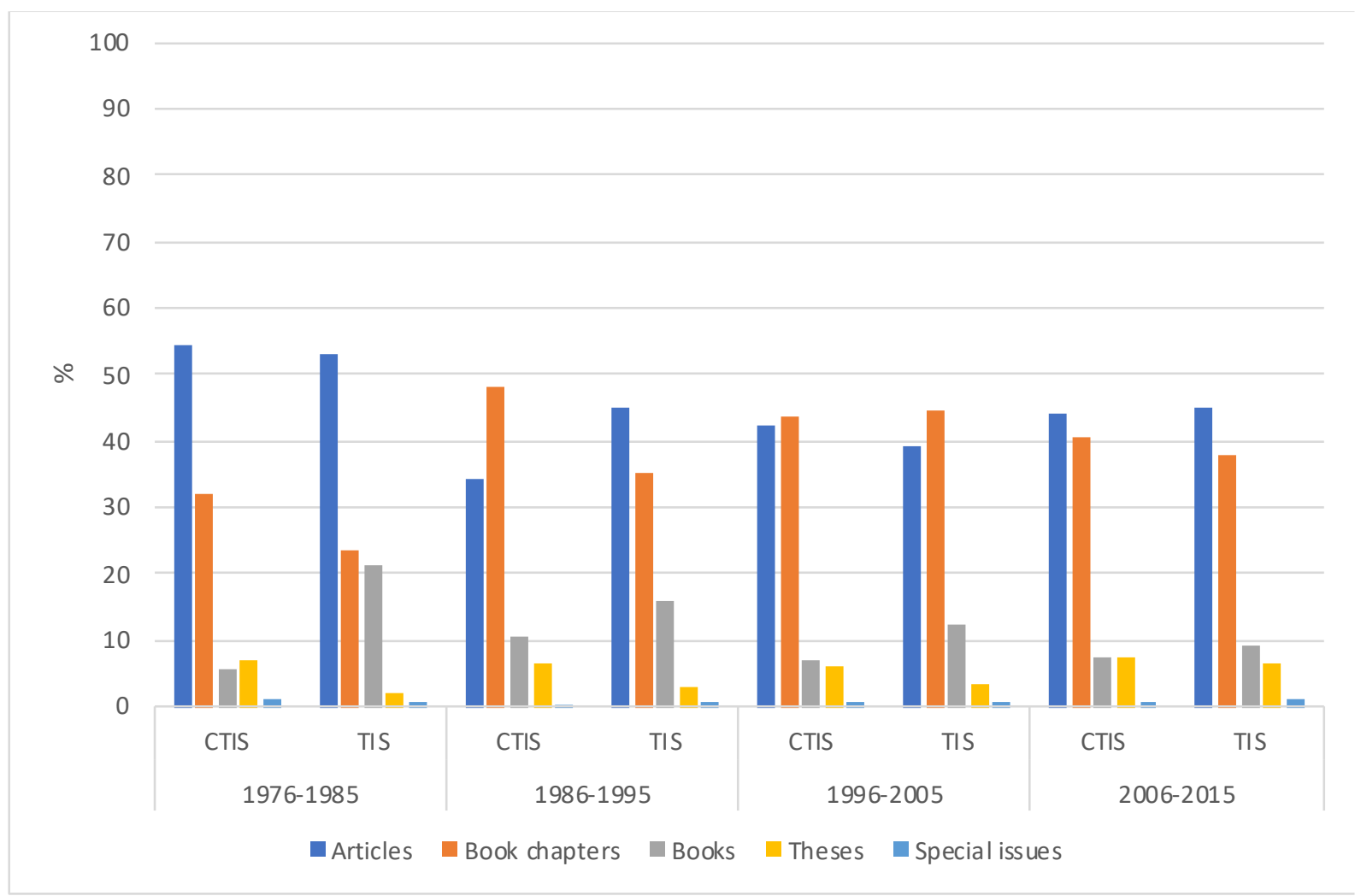

Figure 3. Evolution of publication formats in CTIS and TIS (1976-2015)

\subsection{Authorship in CTIS}

The 2,128 records (2.7\% of CTIS records in TIS) have been written by 1,477 different authors (4.5\%) out of the 33,056 different authors who have published in TIS according to BITRA's data. Table 6 summarizes the mean and the median number of authors per document and of records per author both in CTIS and in TIS from 1976 to 2015. 
Olalla-Soler, C., Franco Aixelá, J., \& Rovira-Esteva, S. (2020). Mapping cognitive translation and interpreting studies: A bibliometric approach. Linguistica Antverpiensia, New Series: Themes in Translation Studies, 19, 25-52.

Table 6. Mean and median number of authors per document and of records per author in CTIS and TIS (1976-2015)

\begin{tabular}{|l|l|l|l|}
\hline Number of & Descriptive statistics & CTIS & TIS \\
\hline authors per document & Mean & 1.4 & 1.2 \\
\hline & SD & 1.2 & 0.7 \\
\hline & $5 \%$ trimmed mean $^{6}$ & 1.3 & 1.1 \\
\hline records per author & Median & 1.0 & 1.0 \\
\hline & Mean & 2 & 2.5 \\
\hline & SD & 3.2 & 5.5 \\
\hline & $5 \%$ trimmed mean & 1.5 & 1.7 \\
\hline$(1,838$ records in CTIS and 68,364 in TIS) & 1.0 & 1.0 \\
\hline
\end{tabular}

CTIS documents are authored by slightly more scholars than TIS documents are, although the difference is too small to be considered relevant. ${ }^{7}$ The inverse tendency is observed regarding the number of records per author: fewer records per author were detected in the case of CTIS than in TIS; however, the difference is again too small. ${ }^{8}$ The explanation might be that CTIS scholars are rather young and therefore the number of publications per author is lower. Another possible reason is that CTIS could be divided into two groups of authors: while the first would be a small group publishing documents devoted mainly to CTIS, the second would be composed of many authors who at some point in their academic career sporadically publish very few documents on CTIS. The results displayed in Figure 4 seem to confirm this explanation.

\subsubsection{Co-authorship}

Out of 1,742 CTIS records indexed in BITRA of texts published from 1976 to 2015, 24.6\% (453) were co-authored, whereas in the case of TIS, 11,270 records (16.5\%) of a total of 68,364 were authored by a minimum of two authors ( $p$-value of the Fisher's exact test $<0.001$ ). Table 7 below summarizes the number of co-authors per document in both CTIS and TIS from 1976 to 2015.

Table 7. Number of co-authors per document in CTIS and TIS (1976-2015)

\begin{tabular}{|l|c|c|}
\hline & CTIS & TIS \\
\hline Mean & 2.8 & 2.5 \\
\hline$S D$ & 1.7 & 1.1 \\
\hline $5 \%$ trimmed mean & 2.5 & 2.3 \\
\hline Median & 2.0 & 2.0 \\
\hline
\end{tabular}

In both CTIS and TIS, $50 \%$ of the co-authored documents are the work of two scholars. However, CTIS documents tend to be authored by slightly more scholars than TIS documents, 
Olalla-Soler, C., Franco Aixelá, J., \& Rovira-Esteva, S. (2020). Mapping cognitive translation and interpreting studies: A bibliometric approach. Linguistica Antverpiensia, New Series: Themes in Translation Studies, 19, 25-52.

hinting at more frequent collaboration networks in CTIS. Still, the difference was too small to be considered relevant from a statistical viewpoint. ${ }^{9}$

To investigate co-authorship patterns, we plotted all CTIS authors who had published at least three documents (194 authors) in a co-authorship network using VOSviewer (see Figure 4). A minimum of three publications was used as a threshold since the median number of documents per author after excluding authors with a single publication was three.

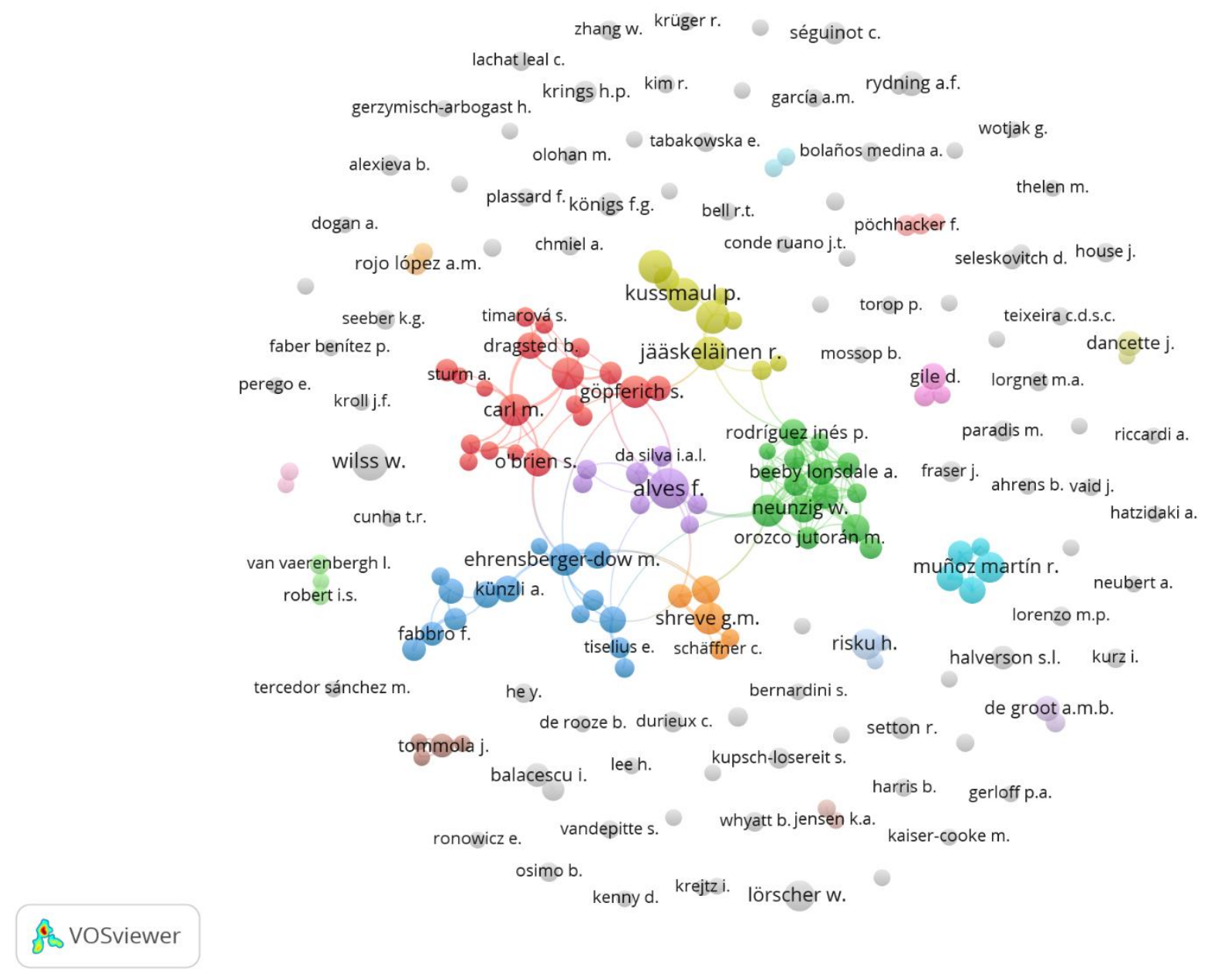

Figure 4. CTIS co-authorship network (1976-2015) ${ }^{10}$

Figure 4 shows strongly related authors close to each other; the more relationships an author has with other authors, the nearer they are plotted in the centre of the network. At the same time, authors are organized in clusters, that is, sets of closely related authors. Each colour represents a cluster. Circle size is proportional to the number of authored documents.

Let us divide this imaginary circle into three concentric areas. In the centre of the plot, the clusters represent highly interrelated authors. In the outer part of the circle we observe two levels: an imaginary middle ring, closer to the interrelated clusters, has some other clusters represented by their most productive author - Balacescu, Gile, Muñoz Martín, Pöchhacker, Robert, Rojo, Risku and Tommola. A second, outer ring at the edge of the circle displays scholars with few (or very few) co-authored works in CTIS. 
Olalla-Soler, C., Franco Aixelá, J., \& Rovira-Esteva, S. (2020). Mapping cognitive translation and interpreting studies: A bibliometric approach. Linguistica Antverpiensia, New Series: Themes in Translation Studies, 19, 25-52.

To investigate the inner circle of the network, we created a second plot in which we included only those authors who were interconnected by co-authorship, employing the same threshold as before (see Figure 5).

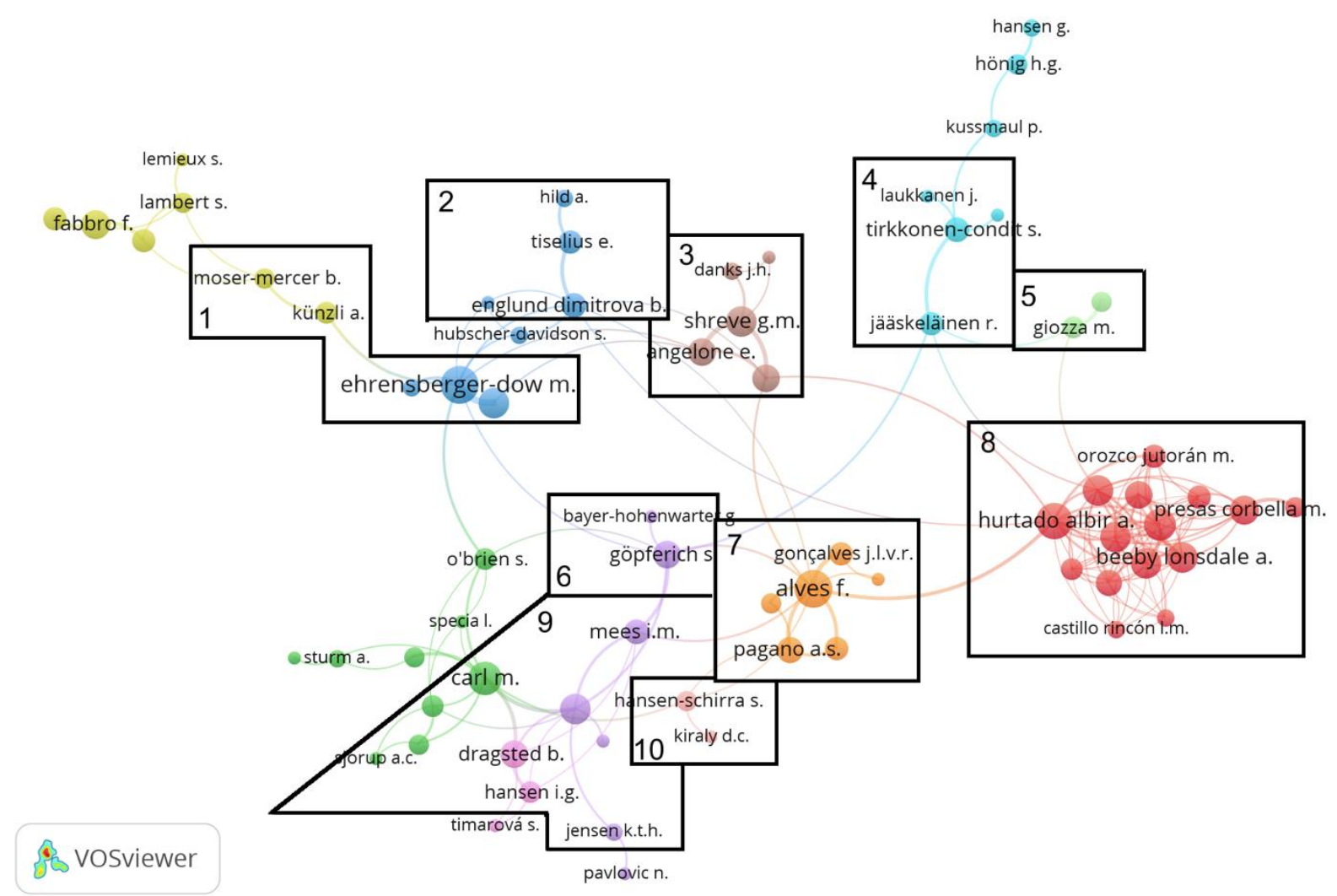

Figure 5. CTIS co-authorship network of interrelated authors (1976-2015)

VOSviewer organized the interrelated authors into 11 clusters using different colours. In some cases, the authors in a cluster work in the same institutions; in others, in the same country. Since most links between authors occur within these frames, it suggests that co-authorship in CTIS is strongly related to the country in which the co-authors are situated or have been based ( 1 = Switzerland; 2 = Sweden; 3 = United States; 4 = Finland; 5 = Argentina (Giozza \& Gatti); $6=$ Austria; $7=$ Brazil; $8=$ Spain; $9=$ Denmark (Jakobsen is represented in the central circle of the cluster); $10=$ Germany). Many co-authorships between members of different clusters plotted in the figure could be due to co-edited volumes. For example, the link between Giozza, Jääskeläinen, Mellinger (name not visible in Figure 5) and Rodríguez-Inés (name not visible) is due to the co-edited journal issue Translation Process Research (Translation \& Interpreting 7(1), 2015); the link between Alves, Hurtado and Lacruz (name not visible) is established due to the co-edited journal issue Cognition \& Behavior: Translation as a cognitive activity (Translation Spaces 4(1), 2015); the link between Ehrensberger-Dow and Englund Dimitrova is due to the co-edited journal issue Cognitive Space: Exploring the situational interface (Translation Spaces 5(1), 2016). While the networks portrayed in Figures 4 and 5 are useful for identifying collaborations between scholars, they present co-authorship relationships only, which is one of the many possible ways to collaborate in academia. 
Olalla-Soler, C., Franco Aixelá, J., \& Rovira-Esteva, S. (2020). Mapping cognitive translation and interpreting studies: A bibliometric approach. Linguistica Antverpiensia, New Series: Themes in Translation Studies, 19, 25-52.

\subsubsection{Most productive authors}

To identify the most productive authors, the ratio of published documents per year for each author was computed by dividing the author's total number of publications by the difference between the year of their most recent publication and the year of their oldest one. Table 8 presents the most productive authors in both CTIS and TIS from 1976 to 2015.

Table 8. Most productive authors in CTIS and TIS. Higher to lower yearly record ratio (1976-2015)

\begin{tabular}{|c|c|c|c|c|c|c|c|c|c|}
\hline \multicolumn{5}{|c|}{ CTIS } & \multicolumn{5}{|c|}{ TIS } \\
\hline \multicolumn{2}{|r|}{ Author } & \multirow{2}{*}{$\begin{array}{l}n \\
22 \\
\end{array}$} & \multirow{2}{*}{$\begin{array}{c}\% \text { total } \\
1.2 \\
\end{array}$} & \multirow{2}{*}{$\begin{array}{c}\text { docs/year } \\
3.1 \\
\end{array}$} & \multicolumn{2}{|r|}{ Author } & \multirow{2}{*}{$\begin{array}{l}n \\
173 \\
\end{array}$} & \multirow{2}{*}{$\begin{array}{c}\% \text { total } \\
0.3 \\
\end{array}$} & \multirow{2}{*}{$\begin{array}{c}\text { docs/year } \\
6.7 \\
\end{array}$} \\
\hline 1 & Carl & & & & 1 & Valero & & & \\
\hline 2 & Alves & 47 & 2.6 & 2.4 & 2 & Pym & 181 & 0.3 & 6.5 \\
\hline 3 & Ehrensberger-Dow & 23 & 1.3 & 2.3 & 3 & Nord & 149 & 0.2 & 5.1 \\
\hline 4 & Göpferich & 22 & 1.2 & 2.0 & 4 & Gile & 169 & 0.2 & 4.7 \\
\hline 5 & O’Brien & 15 & 0.8 & 1.7 & 5 & Pöchhacker & 110 & 0.2 & 4.2 \\
\hline 6 & Hansen & 25 & 1.4 & 1.6 & 6 & Wilss & 120 & 0.2 & 3.8 \\
\hline 7 & Jakobsen & 22 & 1.2 & 1.4 & 7 & House & 130 & 0.2 & 3.4 \\
\hline 8 & Hurtado & 23 & 1.3 & 1.2 & 8 & Snell-Hornby & 123 & 0.2 & 3.2 \\
\hline 9 & Kußmaul & 27 & 1.5 & 1.1 & 9 & Lafarga & 116 & 0.2 & 3.1 \\
\hline 9 & Wilss & 32 & 1.7 & 1.1 & \multirow[t]{4}{*}{10} & \multirow[t]{4}{*}{ Gambier } & \multirow[t]{4}{*}{115} & \multirow[t]{4}{*}{0.2} & \multirow[t]{4}{*}{3.0} \\
\hline 10 & Muñoz Martín & 19 & 1.0 & 1.0 & & & & & \\
\hline 10 & Risku & 19 & 1.0 & 1.0 & & & & & \\
\hline 10 & Shreve & 22 & 1.2 & 1.0 & & & & & \\
\hline
\end{tabular}

Comparing CTIS and TIS in terms of the relative number of publications of the most productive authors in relation to the total number of publications is not meaningful, given the extremely large difference in the absolute number of publications in CTIS $(n=1,838)$ and in TIS ( $n=68,364$ ). However, only one of the CTIS authors (Wilss) is also included in the list of the most productive ones in TIS. For the whole period of analysis, we calculated the mean proportion of CTIS documents produced by CTIS authors in relation to the total number of their publications and we obtained a mean of $55.5 \%$ (median $=50 \% ; S D=37.9$ ). This could also explain why the ratio of records per year is also lower than that of the most productive TIS authors, except for Carl (3.1).

Table 9 presents the most productive authors in CTIS and TIS for the last complete decade of analysis (2006-2015). 
Olalla-Soler, C., Franco Aixelá, J., \& Rovira-Esteva, S. (2020). Mapping cognitive translation and interpreting studies: A bibliometric approach. Linguistica Antverpiensia, New Series: Themes in Translation Studies, 19, 25-52.

Table 9. Most productive CTIS and TIS authors. Higher to lower yearly record ratio (2006-2015)

\begin{tabular}{|c|c|c|c|c|c|c|c|c|c|}
\hline & \multicolumn{4}{|c|}{ CTIS } & & \multicolumn{4}{|c|}{ TIS } \\
\hline & Author & $\mathrm{n}$ & $\%$ total & docs/year & & Author & $\mathrm{n}$ & $\%$ total & docs/year \\
\hline 1 & Carl & 22 & 2.5 & 3.1 & 1 & Valero & 78 & 0.3 & 8.7 \\
\hline 1 & Ehrensberger-Dow & 22 & 2.5 & 3.1 & 2 & Orero & 71 & 0.3 & 7.9 \\
\hline 2 & Angelone & 14 & 1.6 & 2.8 & 3 & Pym & 61 & 0.2 & 6.8 \\
\hline 3 & Alves & 24 & 2.8 & 2.7 & 4 & Gambier & 54 & 0.2 & 6.0 \\
\hline 4 & Göpferich & 20 & 2.3 & 2.5 & 5 & Ortega & 51 & 0.2 & 5.7 \\
\hline 5 & Bayer-Hohenwarter & 11 & 1.3 & 2.2 & 9 & Gallego & 43 & 0.2 & 5.4 \\
\hline 6 & Lacruz & 10 & 1.1 & 2.0 & 6 & House & 47 & 0.2 & 5.2 \\
\hline 6 & Muñoz Martín & 16 & 1.8 & 2.0 & 7 & Pöchhacker & 46 & 0.2 & 5.1 \\
\hline 6 & Shreve & 16 & 1.8 & 2.0 & 8 & Matamala & 45 & 0.2 & 5.0 \\
\hline 7 & Hurtado & 15 & 1.7 & 1.9 & \multirow[t]{7}{*}{10} & \multirow[t]{7}{*}{ Díaz-Cintas } & \multirow[t]{7}{*}{39} & \multirow[t]{7}{*}{0.2} & \multirow[t]{7}{*}{4.3} \\
\hline 8 & Jakobsen & 14 & 1.6 & 1.8 & & & & & \\
\hline 8 & Risku & 9 & 1.0 & 1.8 & & & & & \\
\hline 9 & O’Brien & 15 & 1.7 & 1.7 & & & & & \\
\hline 10 & Dragsted & 11 & 1.3 & 1.6 & & & & & \\
\hline 10 & Hansen & 11 & 1.3 & 1.6 & & & & & \\
\hline 10 & Massey & 11 & 1.3 & 1.6 & & & & & \\
\hline (872 re & cords in CTIS and 26,572 & & & & & & & & \\
\hline
\end{tabular}

A similar tendency is observed when comparing the whole period of analysis (1976-2015) with the 2006-2015 decade, according to the most productive authors in CTIS: the authors in CTIS seem to be less productive than those of TIS because most of them also publish documents related to other research areas and therefore their productivity in CTIS is only a part of their whole academic output. For this period, we calculated the mean proportion of CTIS records produced by CTIS authors in relation to their total number of publications and we obtained a mean of $60.1 \%$ (median $=50 \%$; $S D=36.5$ ). Many of the most productive CTIS authors in the last complete decade (2006-2015) are also some of the most productive during the entire period of the study (Alves, Carl, Ehrensberger-Dow, Göpferich, Hansen, Hurtado, Jakobsen, Muñoz Martín, O’Brien, Risku and Shreve) and, interestingly, in most cases the majority of their production was published in the 2006-2015 period (Alves, 51.1\%; Carl, 100\%; Ehrensberger-Dow, 95.7\%; Göpferich, 90.9\%; Hansen, 44\%; Hurtado, 65.2\%; Jakobsen, 63.6\%; Muñoz Martín, 84.2\%; O’Brien, 100\%; Shreve, 72.3\% and Risku, 47.4\%). This indicates that, as observed in Figure 1, the productivity in CTIS gained momentum in the past decade (20062015). It may also indicate a shift in the type of research conducted in the last complete decade to be analysed. Whereas during the whole period of study most contributions by many of the most productive scholars in CTIS are conceptual or theoretical, in the period ranging from 2006 to 2015 most of the contributions are empirical.

\subsection{Citation patterns in CTIS}

Out of 1,838 CTIS records of documents published from 1976 to 2015, only 37.7\% (693) have no citations. In the case of TIS, the percentage rises to $61.8 \%(42,271$ records out of 68,364$)$. In fact, CTIS documents tend to be cited more frequently (see Table 10) than TIS documents 
Olalla-Soler, C., Franco Aixelá, J., \& Rovira-Esteva, S. (2020). Mapping cognitive translation and interpreting studies: A bibliometric approach. Linguistica Antverpiensia, New Series: Themes in Translation Studies, 19, 25-52.

$(U=38,628,436 ; p<0.001 ; r=0.354)$. When records with no citations are discarded, CTIS documents still are more frequently cited than TIS documents $(U=8,808,564 ; p<0.001$; $r=0.383)$.

Table 10. Citations per document (all) and citations per document with at least one citation in CTIS and TIS (1976-2015)

\begin{tabular}{|l|c|c|c|c|}
\hline & \multicolumn{2}{|c|}{ All records } & \multicolumn{2}{c|}{ Records with $\geq \mathbf{1}$ citation } \\
\hline & CTIS & TIS & CTIS & TIS \\
\hline Median & 0.5 & 0.2 & 1.1 & 0.5 \\
\hline Mean & 1.2 & 0.4 & 1.9 & 1.0 \\
\hline$S D$ & 2.2 & 1.2 & 2.5 & 1.7 \\
\hline $5 \%$ trimmed mean & 0.9 & 0.2 & 1.6 & 0.7 \\
\hline (1,838 records in CTIS and 68,364 in TIS)
\end{tabular}

Whereas $50 \%$ of TIS documents received their first citation 6.1 years after publication (see Table 11; median), 50\% of CTIS documents received it slightly earlier: 5.7 years after publication $(U=11,894,956 ; p<0.001 ; r=0.630)$. This is possibly because CTIS is a rather small research community composed of $1,477(4.5 \%)$ of the 33,056 authors who have published in TIS. This makes it relatively easy to be aware of the newest publications in the sub-field. It also makes it easier to cite newer research than in a larger discipline that encompasses as many research areas as TIS does. Furthermore, many of the publications in CTIS are (co-) edited volumes derived from events such as conferences and workshops where the latest, up-to-date investigations are presented, and this could also speed up the rate of first citation.

Table 11. Citation latency in CTIS and TIS (1976-2015)

\begin{tabular}{|l|c|c|}
\hline Citation latency & CTIS & TIS \\
\hline Median & 5.7 & 6.1 \\
\hline Mean & 6.6 & 7.6 \\
\hline SD & 3.8 & 4.8 \\
\hline $5 \%$ trimmed mean & 6.2 & 7.1 \\
\hline Mode $^{11}$ (first citation peak) & 5.8 & 4.1 \\
\hline
\end{tabular}

Whereas the first citation arrives earlier for CTIS documents, the cited half-life of both CTIS and TIS documents (see Table 12$)$ is similar $(U=250,778,453.5 ; p=0.060 ; r=0.432)$.

Table 12. Cited half-life of CTIS and TIS documents (1976-2015)

\begin{tabular}{|l|c|c|}
\hline Cited half-life & CTIS & TIS \\
\hline Median & 7.6 & 7.7 \\
\hline Median absolute deviation & 2.8 & 2.9 \\
\hline Mode (citation peak) & 4.7 & 5.3 \\
\hline
\end{tabular}

Figure 6 expands the results presented in Tables 11 and 12 by displaying the likelihood of their being cited for the first time during the entire period (left plot) and also the likelihood of their 
Olalla-Soler, C., Franco Aixelá, J., \& Rovira-Esteva, S. (2020). Mapping cognitive translation and interpreting studies: A bibliometric approach. Linguistica Antverpiensia, New Series: Themes in Translation Studies, 19, 25-52.

being cited repeatedly during this same period (right plot). The left plot shows that the likelihood of being cited for the first time is high for both CTIS and TIS documents until the sixth year (when a likelihood of $50 \%$ is reached), and it then rapidly decreases between the sixth and the 12th years, although more markedly so in the case of CTIS. After the 12th year, the probability decreases gradually. No relevant differences are observable in the right plot: both CTIS and TIS documents age similarly, with a high probability of their being cited until the tenth year (when a likelihood of $50 \%$ is reached), a marked decrease from years ten to 18 , and a gradual decrease after the 18th year. This shows that, whereas CTIS is a comparatively small research community that tends to cite new publications faster than the TIS community (see Table 11), the obsolescence of publications devoted to CTIS is similar to that of TIS documents.
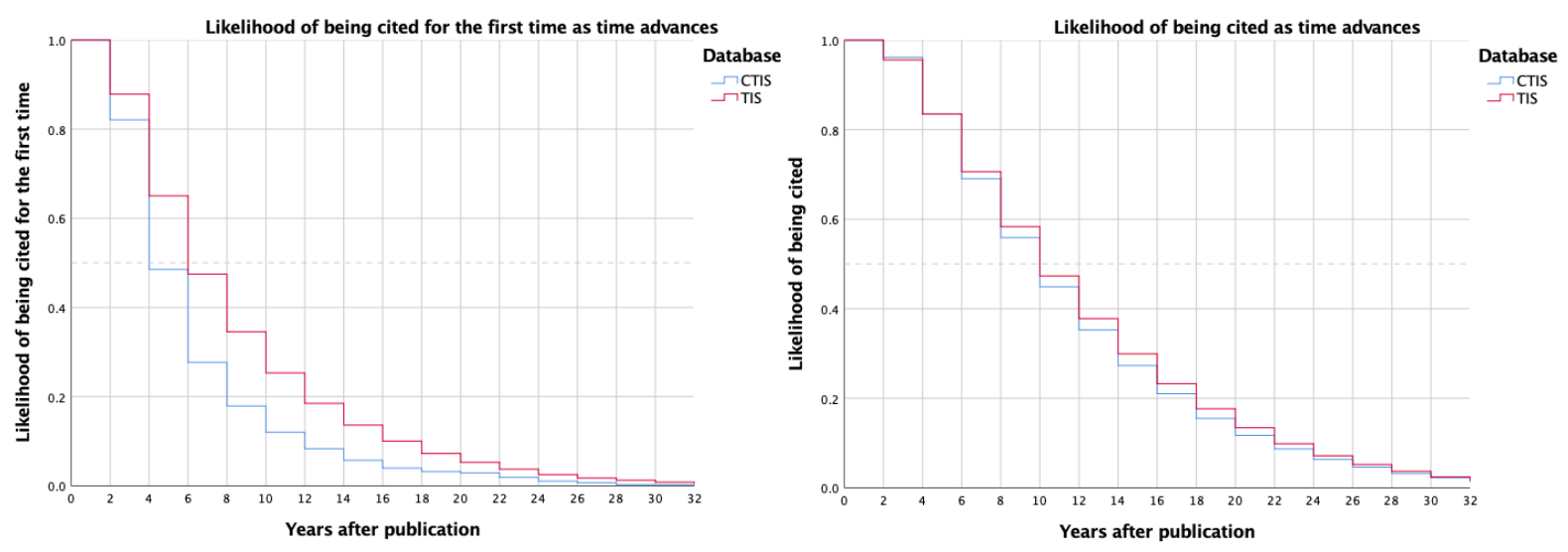

Figure 6. Probability of being cited for the first time (left) or being cited over time (right) in both CTIS and TIS (1976-2015)

\subsubsection{Most-cited authors and publications}

To identify the most-cited authors, the ratio of accrued citations per year for each author was computed by dividing the author's total number of accrued citations by the difference between the publication year of their most recent document and that of their oldest document. In both CTIS and TIS, the most frequently cited authors (see Table 13) have a longstanding tradition in the discipline, and some of their publications are considered key works since they are also some of the most frequently cited publications (see Table 15). It is worth noting that a majority of the most cited authors who have focused on the cognitive aspects of translation come from German-speaking and Scandinavian countries, which might indicate the geographical origin of CTIS, at least as regards written translation.

Not many of the most-cited authors in CTIS (see Table 13) are the most productive (see Table 9). The exceptions are Jääskeläinen, Jakobsen, Kußmaul, Lörscher and Shreve. This could indicate that many of the most-cited authors are listed here because they published few but very impactful documents (mainly generalist theoretically oriented books; see Table 15) that could be considered seminal works in CTIS. Again, comparing CTIS to TIS according to the relative number of citations of the most-cited authors in relation to the total number of 
Olalla-Soler, C., Franco Aixelá, J., \& Rovira-Esteva, S. (2020). Mapping cognitive translation and interpreting studies: A bibliometric approach. Linguistica Antverpiensia, New Series: Themes in Translation Studies, 19, 25-52.

citations is not appropriate, given the extremely large difference in the absolute number of citations and potential citers in CTIS and TIS. However, none of the most-cited authors in CTIS is listed as one of the most-cited authors in TIS, and the ratio of accrued citations per year is also lower than that in TIS. This could indicate that CTIS cannot be considered a general research area in TIS but a clearly specialized sub-discipline with its own (relatively reduced) readership.

Table 13. Most frequently cited authors in CTIS and TIS. Highest to lowest ratio of citations per year (1976-2015)

\begin{tabular}{|r|l|c|c|r|l|c|c|}
\hline & \multicolumn{3}{|c|}{ CTIS } & \multicolumn{3}{c|}{ TIS } \\
\hline & Author & Citations & Citations/year & & Author & Citations & Citations/year \\
\hline 1 & PACTE & 303 & 20.2 & 1 & Venuti & 1,595 & 61.3 \\
\hline 2 & Gutt & 199 & 18.1 & 2 & Toury & 1,810 & 51.7 \\
\hline 3 & Kußmaul & 363 & 14.5 & 3 & Lefevere & 1,112 & 48.3 \\
\hline 4 & Krings & 267 & 14.1 & 4 & Pym & 1,271 & 45.4 \\
\hline 5 & Jakobsen & 208 & 13.9 & 5 & Baker & 1,464 & 43.1 \\
\hline 6 & Tirkkonen-Condit & 252 & 10.5 & 6 & Nord & 1,200 & 41.4 \\
\hline 7 & Jääskeläinen & 281 & 10.0 & 7 & Bassnett & 1,111 & 30.9 \\
\hline 8 & Shreve & 197 & 9.4 & 8 & Vermeer & 916 & 29.5 \\
\hline 9 & Lörscher & 214 & 8.2 & 9 & Gile & 967 & 26.9 \\
\hline 10 & Koller & 184 & 7.4 & 10 & Chesterman & 919 & 24.8 \\
\hline
\end{tabular}

The same tendency in CTIS towards concentrating most citations in a low number of authors is also present in the 2006-2015 period (see Table 14): in CTIS, the ten most frequently cited authors account for $21.6 \%$ (830) of the 3,851 citations to CTIS authors, whereas in the case of TIS the percentage rises to only $6.9 \%$ (29,811 citations in total). In this period of analysis, only one CTIS author (Göpferich) is listed as one of the most-cited authors in TIS.

Table 14. Most frequently cited authors in CTIS and TIS. Highest to lowest ratio of citations per year (2006-2015)

\begin{tabular}{|r|l|c|c|c|l|c|c|}
\hline & \multicolumn{3}{|c|}{ CTIS } & & \multicolumn{3}{c|}{ TIS } \\
\hline & Author & Citations & Citations/year & & Author & Citations & Citations/year \\
\hline 1 & Göpferich & 147 & 18.4 & 1 & Pym & 363 & 40.3 \\
\hline 2 & PACTE & 103 & 14.7 & 2 & Baker & 299 & 33.2 \\
\hline 3 & Angelone & 71 & 14.2 & 3 & Díaz-Cintas & 236 & 26.2 \\
\hline 4 & O'Brien & 110 & 12.2 & 4 & Orero & 193 & 21.4 \\
\hline 5 & Alves & 91 & 10.1 & 5 & Göpferich & 160 & 20.0 \\
\hline 6 & Shreve & 79 & 9.9 & 6 & O'Brien & 179 & 19.9 \\
\hline 7 & Jakobsen & 58 & 8.3 & 6 & Tymoczko & 159 & 19.9 \\
\hline 8 & Dragsted & 53 & 7.6 & 7 & Remael & 173 & 19.2 \\
\hline 8 & Hurtado & 7.6 & 8 & Gambier & 163 & 18.1 \\
\hline 9 & Muñoz Martín & 57 & 7.1 & 9 & Hale & 145 & 16.1 \\
\hline 10 & Jääskeläinen & 43 & 4.8 & 10 & Cronin & 132 & 14.7 \\
\hline
\end{tabular}


Olalla-Soler, C., Franco Aixelá, J., \& Rovira-Esteva, S. (2020). Mapping cognitive translation and interpreting studies: A bibliometric approach. Linguistica Antverpiensia, New Series: Themes in Translation Studies, 19, 25-52.

The most frequently cited publications in CTIS and TIS for the whole period of analysis (19762015) are listed in Table 15. The ratio of accrued citations per year was computed by dividing the total number of citations by the time elapsed since the document's year of publication (2015 publication year). Most of the authors listed in Table 14 are also listed in Table 15. These publications may be considered some of the core documents of CTIS and TIS respectively. In both CTIS and TIS, almost all the records are of theoretically oriented books, almost all are available in English and, with very few exceptions, they are authored by a single scholar. These records therefore match the characteristics of CTIS and TIS publications identified in the previous sections.

Table 15. Most frequently cited publications in CTIS and TIS. Highest to lowest ratio of citations per year (1976-2015)

\begin{tabular}{|c|c|c|c|c|c|c|c|}
\hline & \multicolumn{3}{|l|}{ CTIS } & & \multicolumn{3}{|l|}{ TIS } \\
\hline & Publication & Cit. & Cit./year & & Publication & Cit. & Cit./year \\
\hline 1 & $\begin{array}{l}\text { Gutt. 1991. Translation } \\
\text { and Relevance }\end{array}$ & 186 & 7.8 & 1 & $\begin{array}{l}\text { Toury. 1995. Descriptive } \\
\text { Translation Studies - and } \\
\text { Beyond }\end{array}$ & 937 & 46.9 \\
\hline 2 & $\begin{array}{l}\text { PACTE. 2003. Building a } \\
\text { Translation Competence } \\
\text { Model }\end{array}$ & 87 & 7.3 & 2 & $\begin{array}{l}\text { Venuti. 1995. The Translator's } \\
\text { Invisibility }\end{array}$ & 675 & 33.8 \\
\hline 3 & $\begin{array}{l}\text { Englund Dimitrova. } 2003 . \\
\text { Expertise and Explicitation } \\
\text { in the Translation Process }\end{array}$ & 80 & 6.7 & 3 & $\begin{array}{l}\text { Nord. 1997. Translating as a } \\
\text { Purposeful Activity }\end{array}$ & 341 & 18.9 \\
\hline 4 & $\begin{array}{l}\text { Kiraly. 1995. Pathways to } \\
\text { Translation }\end{array}$ & 130 & 6.5 & 4 & $\begin{array}{l}\text { Venuti. 1998. The Scandals of } \\
\text { Translation }\end{array}$ & 320 & 18.8 \\
\hline 5 & $\begin{array}{l}\text { Pym. 2003. Redefining } \\
\text { Translation Competence in } \\
\text { an Electronic Age }\end{array}$ & 62 & 5.2 & 5 & $\begin{array}{l}\text { Hatim; Mason. 1990. Discourse } \\
\text { and the Translator }\end{array}$ & 359 & 14.4 \\
\hline 6 & $\begin{array}{l}\text { Krings. 1986. Was in den } \\
\text { Köpfen von Übersetzern } \\
\text { vorgeht }\end{array}$ & 137 & 4.7 & 6 & $\begin{array}{l}\text { Lefevere. 1992. Translation, } \\
\text { Rewriting and the Manipulation } \\
\text { of Literary Fame }\end{array}$ & 311 & 13.5 \\
\hline 7 & $\begin{array}{l}\text { Lörscher. } 1991 . \\
\text { Translation Performance. }\end{array}$ & 103 & 4.3 & 7 & $\begin{array}{l}\text { Nord. 1988. Textanalyse und } \\
\text { Übersetzen }\end{array}$ & 360 & 13.3 \\
\hline 8 & $\begin{array}{l}\text { Setton. } 1999 . \\
\text { Simultaneous } \\
\text { Interpretation }\end{array}$ & 61 & 3.8 & 8 & Baker. 1992. In Other Words & 296 & 12.9 \\
\hline 9 & $\begin{array}{l}\text { Seleskovitch; Lederer. } \\
\text { 1984. Interpréter pour } \\
\text { traduire }\end{array}$ & 92 & 3.0 & 9 & $\begin{array}{l}\text { Newmark. 1987. A Textbook of } \\
\text { Translation }\end{array}$ & 354 & 12.6 \\
\hline 10 & $\begin{array}{l}\text { Harris; Sherwood. } 1978 . \\
\text { Translating as an Innate } \\
\text { Skill }\end{array}$ & 59 & 1.6 & 10 & $\begin{array}{l}\text { Reiss; Vermeer. } 1984 . \\
\text { Grundlegung einer allgemeinen } \\
\text { Translationstheorie }\end{array}$ & 342 & 11.0 \\
\hline
\end{tabular}


Olalla-Soler, C., Franco Aixelá, J., \& Rovira-Esteva, S. (2020). Mapping cognitive translation and interpreting studies: A bibliometric approach. Linguistica Antverpiensia, New Series: Themes in Translation Studies, 19, 25-52.

\subsection{Accessibility of CTIS documents}

The proportion of open-access (OA) documents published in CTIS from 1976 to 2015 (28.6\%; $525)$ is very similar to that in TIS $(28.8 \% ; 19,674 ; p$-value of the Fisher's exact test $=0.854)$. In CTIS, the proportion of journal articles published in OA reaches $47.8 \%$ versus $48.7 \%$ in TIS (Franco Aixelá et al., in press). Mikki (2017) established that, in the social sciences and in the humanities, journal articles published in OA reach $58 \%$ and $55 \%$, respectively. For this reason, the values in CTIS and in TIS are slightly lower than those in Mikki's study: the global ratio of OA in both TIS and CTIS is lower probably because books and book chapters are very frequent publication formats in TIS, and these two formats are generally published in toll access (OA book chapters in CTIS $=9.9 \%$ and in TIS $=11.0 \%$; OA books in CTIS $=3.5 \%$ and in $\mathrm{TIS}=4.1 \%$ ).

From a diachronic perspective (see Figure 7), CTIS does not differ greatly from TIS in terms of accessibility. However, the figures for 1976-1985 and 1986-1995 must be interpreted with caution, since OA repositories did not exist at that time. These values therefore represent documents that have been digitalized and uploaded to OA repositories years after their actual publication.

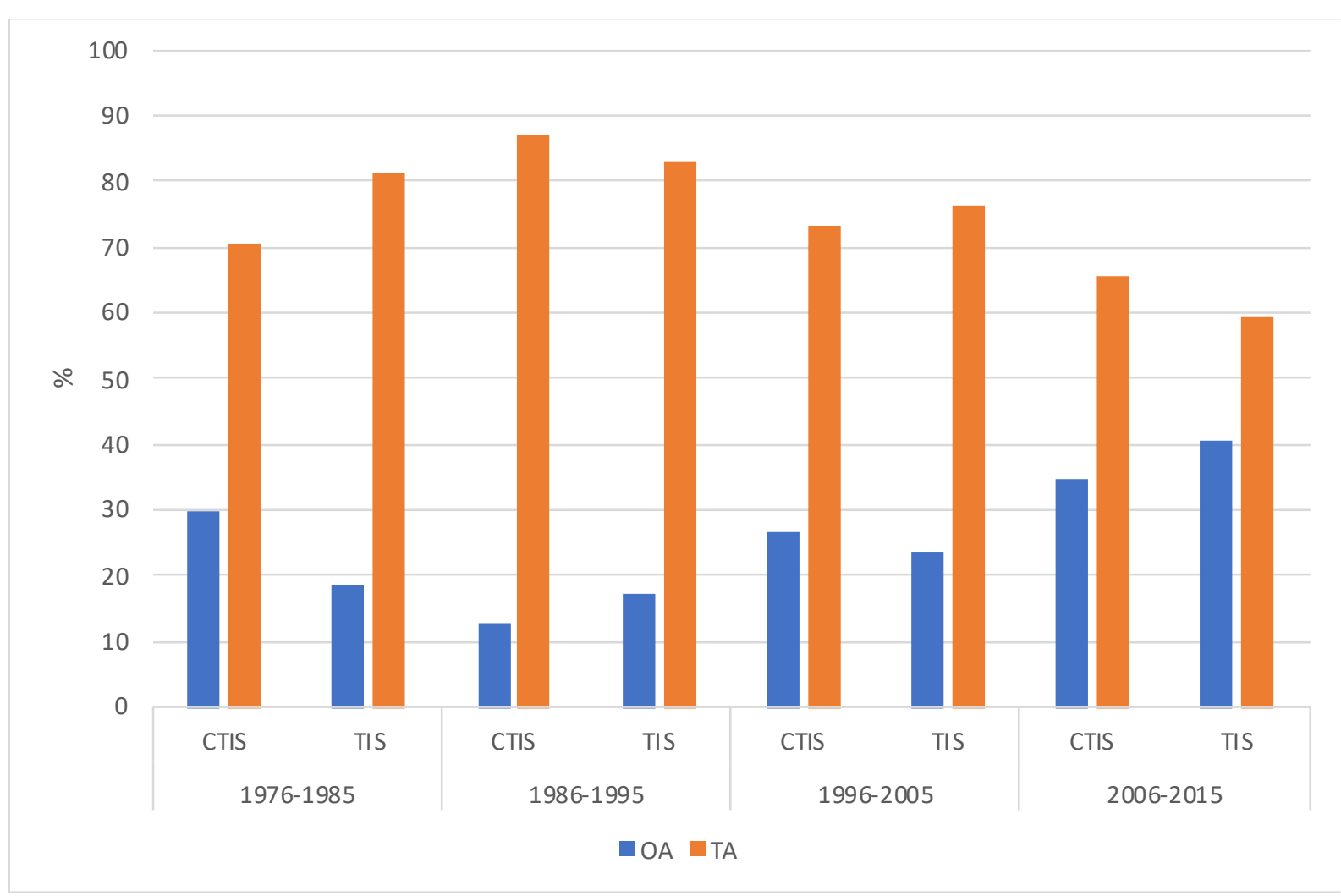

Figure 7. Evolution of the accessibility of CTIS and TIS publications (1976-2015)

\section{Conclusions}

The main objectives of this article were (1) to describe and explain the evolution of CTIS from its inception and (2) to identify specific characteristics of CTIS as a branch of TIS. Applying a bibliometric approach, we identified three development phases of CTIS: a seminal phase (until 
Olalla-Soler, C., Franco Aixelá, J., \& Rovira-Esteva, S. (2020). Mapping cognitive translation and interpreting studies: A bibliometric approach. Linguistica Antverpiensia, New Series: Themes in Translation Studies, 19, 25-52.

approximately 1975), an initial phase (from 1976 to 1995) and a rooting phase (from about 1996 to date). We also observed that the ratio of CTIS documents within TIS has grown over time. The topics investigated in CTIS tend to concentrate on fewer areas than is the case in TIS: CTIS research is largely based on linguistics as a conceptual framework (psycholinguistics, cognitive linguistics and neurolinguistics).

In terms of publication languages, CTIS makes use of English to a greater extent than TIS. German, especially in the first stages of research in this area, was also slightly more present in CTIS, possibly because the origins of (C)TIS were based in German-speaking and Scandinavian countries, at least in the case of cognitive investigations into written translation. Whereas books in TIS are more frequent than in CTIS, book chapters are slightly more frequent in CTIS than in TIS. This could indicate that CTIS books tend to be co-edited volumes generally as a result of academic events, such as proceedings from numerous panels at conferences, specific conferences or workshops. PhD theses are also slightly more frequent in CTIS than in TIS, which could indicate that many young scholars are interested in CTIS research and that it is a rather young research area.

Co-authorship in CTIS is more frequent than in TIS. However, CTIS researchers tend to publish fewer documents per author than TIS researchers, possibly because CTIS is divided between a small group of authors who focus their research on CTIS and a larger group of authors who sporadically publish very few documents devoted to CTIS because their research areas are diverse. This hypothesis was supported by the network analysis of co-authorship we conducted, where we observed that collaboration in CTIS is generally restricted to the country in which the co-authors work.

Another possible explanation is that, given that CTIS is largely based on empirical research, scholars require more time to design and carry out their studies and therefore it takes more time to submit new contributions for publication.

Regarding citations, CTIS documents tend to receive more than TIS documents. Possibly the higher proportion of co-authored documents in CTIS than in TIS has an effect on this, since co-authorship tends to provide a citation advantage over single-authored documents (Biscaro \& Giupponi, 2014).

These facts could indicate that CTIS is a specialized sub-discipline of TIS with its own citation (and co-citation) patterns and its own readership. We hope that the present report will inspire future bibliometric studies on CTIS.

There are many possible ways of expanding this research. First, the abstracts of CTIS publications could be employed to detect and classify content words further. Classifying content words from the abstract and not from the title could help to obtain a richer and more complete map of the frameworks, methods, participants and research topics in CTIS. This could also be studied diachronically to help us understand how CTIS has evolved, and network visualization software could be used to examine the ways in which these content words from different categories are interrelated. 
Olalla-Soler, C., Franco Aixelá, J., \& Rovira-Esteva, S. (2020). Mapping cognitive translation and interpreting studies: A bibliometric approach. Linguistica Antverpiensia, New Series: Themes in Translation Studies, 19, 25-52.

Second, it would be necessary to perform a deeper analysis of citation patterns in CTIS by including co-citation networks. This could help to identify further impactful documents and the flow of ideas and topics among documents. Third, cognitive investigations into translation and interpreting should be examined in separate studies, possibly from a less bibliometric and a more historiographic perspective. Given that the pool of authors investigating cognitive aspects of translation is bigger than that of interpreting (and therefore the corpus of records is also different in size), the bibliometric indicators used in this study have provided results that in some cases do not wholly show the evolution of the interpreting side of CTIS. Employing a historiographic perspective (or combining it with a bibliometric one) would allow for more nuanced descriptions of the evolution of this sub-discipline and could reflect the specific trends of interpreting and translation.

Regarding limitations, only $10 \%$ of the references included in BITRA have been mined for their citations. While this represents more than 100,000 citations, higher percentages of mined citations might yield slightly different trends. Moreover, for operational (and academic) reasons, mining the citations in records in BITRA is more frequent for citing documents published from 2006 onwards as journal articles in open access. BITRA also excludes selfcitations, which could be a disadvantage for co-authored documents. Finally, the coverage of publications in Western languages is larger than that of Eastern languages, as happens to different degrees with all Western-based international databases.

All in all, our data show that CTIS has many features that would allow us to classify it as a selfstanding sub-discipline within TIS. CTIS has expanded greatly in the past few decades, and it will probably continue to do so in view of the numerous academic events being organized and planned for the years to come. CTIS already has a long-standing tradition in the West, and it is growing at a fast pace in the East, as shown by the six editions of the annual International Conference on Cognitive Research on Translation and Interpreting that takes place in China. It is therefore of paramount importance that the databases employed for future bibliometric studies also provide adequate coverage of the research devoted to CTIS and carried out in Eastern countries in their own languages and publication venues. The results presented in this article may work as a first bibliometric peek into the CTIS landscape and can perhaps provide a point of departure for future bibliometric studies in this field.

\section{References}

Alves, F. (Ed.). (2003). Triangulating translation: Perspectives in process-oriented research. John Benjamins. https://doi.org/10.1075/btl.45

Biscaro, C., \& Giupponi, C. (2014). Co-authorship and bibliographic coupling network effects on citations. PLoS ONE, 9(6). Article e99502. https://doi.org/10.1371/journal.pone.0099502

Cooke, S., \& Donaldson M. R. (2014). Self-citation by researchers: Narcissism or an inevitable outcome of a cohesive and sustained research program? Ideas in Ecology and Evolution, 7(1), 1-2. https://doi.org/10.4033/iee.2014.7.1.e

De Bellis, N. (2009). Bibliometrics and citation analysis: From the science citation index to cybermetrics. Scarecrow Press. 
Olalla-Soler, C., Franco Aixelá, J., \& Rovira-Esteva, S. (2020). Mapping cognitive translation and interpreting studies: A bibliometric approach. Linguistica Antverpiensia, New Series: Themes in Translation Studies, 19, 25-52.

Díaz Cintas, J., \& Massidda, S. (2019). Technological advances in audiovisual translation. In M. O'Hagan (Ed.), The Routledge handbook of translation and technology (pp. 255-270). Routledge. https://doi.org/10.4324/9781315311258-15

Ellis, P. D. (2010). The essential guide to effect sizes: Statistical power, meta-analysis, and the interpretation of research results. Cambridge University Press. https://doi.org/10.1017/ CBO9780511761676

Franco Aixelá, J. (2001-2020). BITRA: Bibliografía de interpretación y traducción. https://doi.org/10. $14198 /$ bitra

Franco Aixelá, J., Olalla-Soler, C., \& Rovira-Esteva, S. (in press). Open access in translation studies: A bibliometric overview of its distribution and development. Translation \& Interpreting, 13(1).

Gambier, Y., \& van Doorslaer, L. (2016). Disciplinary dialogues with translation studies: The background chapter. In Y. Gambier \& L. van Doorslaer (Ed.), Border crossings: Translation studies and other disciplines (pp. 1-22). John Benjamins. https://doi.org/10.1075/btl.126.01gam

Gambier, Y., \& van Doorslaer, L. (Eds.). (2020). Translation studies bibliography. https://doi.org/10. $1075 /$ etsb

Göpferich, S., Jakobson, A. L., \& Mees, I. (Eds.). (2009). Behind the mind: Methods, models and results in translation process research. Samfundslitteratur.

Jääskeläinen, R., \& Lacruz, I. (2018). Translation - cognition - affect - and beyond: Reflections on an expanding field of research. In I. Lacruz \& R. Jääskeläinen (Eds.), Innovation and expansion in translation process research (pp. 1-16). John Benjamins. https://doi.org/10.1075/ata.18.01jaa

Jakobsen, A. L. (2014). The development and current state of translation process research. In E. Brems, R. Meylaerts, \& L. van Doorslaer, L. (Eds.), The known unknowns of translation studies (pp. 6588). John Benjamins. https://doi.org/10.1075/bct.69.05jak

Mikki, S. (2017). Scholarly publications beyond pay-walls: Increased citation advantage for open publishing. Scientometrics, 113(3), 1529-1538. https://doi.org/10.1007/s11192-017-2554-0

Moed, H. F., Van Leeuwen, T. N., \& Reedijk, J. (1999). Towards appropriate indicators of journal impact. Scientometrics, 46(3), 575-589. https://doi.org/10.1007/BF02459613

Muñoz Martín, R. (2014a). A blurred snapshot of advances in translation process research. MonTI. Monographs in Translation and Interpreting, 1, 49-84. http://dx.doi.org/10.6035/MonTI. 2014.ne1.1

Muñoz Martín, R. (Ed.). (2014b). Minding translation [Special issue]. MonTI. Monographs in Translation and Interpreting, 1. http://dx.doi.org/10.6035/MonTI.2014.ne1

Muñoz Martín, R. (Ed.). (2016a). Reembedding translation process research. John Benjamins. https://doi.org/10.1075/btl.128

Muñoz Martín, R. (2016b). Reembedding translation process research: An introduction. In R. Muñoz Martín (Ed.), Reembedding translation process research (pp. 11-19). John Benjamins. https://doi.org/10.1075/btl.128.01mun

Perianes-Rodriguez, A., Waltman, L., \& van Eck, N. J. (2016). Constructing bibliometric networks: A comparison between full and fractional counting. Journal of Informetrics, 10(4), 1178-1195. https://doi.org/10.1016/i.joi.2016.10.006

Rovira-Esteva, S., \& Franco Aixelá, J. (2018). Bibliometric tools: Evaluation, mapping. In L. D’hulst \& Y. Gambier (Eds.), A history of modern translation knowledge: Sources, concepts, effects (pp. 117-122). John Benjamins. https://doi.org/10.1075/btl.142.15rov

Rovira-Esteva, S., Franco Aixelá J., \& Olalla-Soler, C. (2019). Citation patterns in translation studies: A format-dependent bibliometric analysis. Translation \& Interpreting, 11(1), 147-171. https://doi.org/10.12807/ti.111201.2019.a09 
Olalla-Soler, C., Franco Aixelá, J., \& Rovira-Esteva, S. (2020). Mapping cognitive translation and interpreting studies: A bibliometric approach. Linguistica Antverpiensia, New Series: Themes in Translation Studies, 19, 25-52.

Schöpfel, J., \& Farace, D.J. (2010). Grey literature. In M. J. Bates \& M. N. Maack (Eds.), Encyclopedia of library and information sciences (3rd ed., pp. 2029-2039). CRC Press. https://doi.org/ 10.1081/E-ELIS3-120043732

Schwieter, J. W., \& Ferreira, A. (Eds.). (2017). The handbook of translation and cognition. Wiley Blackwell. https://doi.org/10.1002/9781119241485

Snell-Hornby, M. (2006). The turns of translation studies: New paradigms or shifting viewpoints? John Benjamins. https://doi.org/10.1075/btl.66

van Eck, N. J., \& Waltman, L. (2010). Software survey: VOSviewer, a computer program for bibliometric mapping. Scientometrics, 84(2), 523-538. https://doi.org/10.1007/s11192-009-0146-3

\footnotetext{
${ }^{1}$ Meta, Interpreting, Target, Across Languages and Cultures, Translation and Interpreting Studies, Perspectives, The Translator, Hermes, TTR, The Interpreter and Translator Trainer, Babel, Machine Translation, New Voices in Translation Studies and Translation Studies.
}

2 Source: BITRA (2001-2020).

${ }^{3}$ Cf. https://dti.ua.es/en/bitra/impact.html for further information.

${ }^{4}$ Thematic labels in BITRA are frequently presented at two levels in order to include both general areas and their most investigated items or modes. For instance, all articles dealing with simultaneous interpreting are tagged both as Interpreting (general level) and as Simultaneous (specific mode). This way, we can gain access to all documents dealing with interpreting (irrespective of the particular mode) or only to those covering simultaneous interpreting. The same happens, for instance, with Problem and Metaphor or with Genre and Legal.

${ }^{5}$ A test of homogeneity indicated that the distribution of the frequency of publication formats was different between CTIS and TIS $\left(\chi^{2}[4]=65.4, p<0.001\right)$; however, the effect size was extremely small $(V=0.029)$ and as a result the significant result was discarded.

${ }^{6}$ When data are skewed, the mean may not be a proper indicator of central tendency. Whereas the median is a more conservative one, the trimmed mean excludes the lowest and highest data at a specific percentage. Therefore, a $5 \%$ trimmed mean excludes the lowest $5 \%$ and the highest $5 \%$ of the data, providing a relatively more conservative indicator of central tendency than the mean but a relatively less conservative one than the median.

${ }^{7}$ A Mann-Whitney $U$ test indicated that there was a statistically significant difference, but the effect size was extremely small $(U=54,679,227.5 ; p<0.001, r=0.118)$ and therefore the significant result was discarded.

${ }^{8} \mathrm{~A}$ Mann-Whitney $U$ test indicated that there was a statistically significant difference, but the effect size was extremely small $(U=20,524,990 ; p<0.001, r=0.060)$ and therefore the significant result was discarded.

${ }^{9}$ A Mann-Whitney $U$ test indicated that there was a statistically significant difference, but the effect size was extremely small $(U=2,057,537.5 ; p<0.001, r=0.060)$ and therefore the significant result was discarded.

10 VOSviewer automatically shifts uppercase to lowercase to avoid unnecessary repetitions resulting from database inconsistencies.

11 In a dataset, the mode is the value (or the category) that is repeated the most. In our study, therefore, the mode represents the citation peak, that is, the year in which most citations occur.

${ }^{12}$ Citations from PACTE have been excluded, because the research group was considered a single author. 